\title{
Comparing synaptic proteomes across seven mouse models for autism reveals molecular subtypes and deficits in Rho GTPase signaling
}

\author{
Abigail U. Carbonell ${ }^{1}$, Carmen Freire-Cobo', Ilana V. Deyneko1, Hediye Erdjument-Bromage ${ }^{3}$, \\ Amy E. Clipperton-Allen ${ }^{4}$, Randall L. Rasmusson ${ }^{5}$, Damon T. Page ${ }^{4}$, Thomas A. Neubert ${ }^{3}$, and \\ Bryen A. Jordan ${ }^{1,2 *}$ \\ ${ }^{1}$ Dominick P. Purpura Department of Neuroscience, ${ }^{2}$ Department of Psychiatry and Behavioral Sciences, \\ Albert Einstein College of Medicine, Bronx, NY, USA. \\ ${ }^{3}$ Department of Cell Biology and Kimmel Center for Biology and Medicine at the Skirball Institute, \\ New York University School of Medicine, New York, NY, USA. \\ ${ }^{4}$ Department of Neuroscience, The Scripps Research Institute Florida, Jupiter, FL, USA. \\ ${ }^{5}$ Department of Physiology and Biophysics, Jacobs School of Medicine \& Biomedical Sciences, \\ University at Buffalo, Buffalo, NY, USA. \\ *Corresponding author and lead contact: \\ Bryen A. Jordan, Ph.D. \\ Dominick P. Purpura Department of Neuroscience \\ Albert Einstein College of Medicine \\ 1300 Morris Park Avenue \\ Rose F. Kennedy Center, Room 825 \\ Bronx, NY 10461 \\ Telephone: (718) 430-2675 \\ E-mail: bryen.jordan@einsteinmed.org
}

Keywords: proteomic, PSD, autism, mouse model, Rho GTPase, Rac, tandem mass tags, TMT

\section{Author Contributions:}

AUC, CFC, IVD, and BAJ designed and performed postsynaptic fractionation in autism mouse models. HEB and TAN performed tandem-mass-tag mass spectrometry and protein identification. AUC and IVD performed bioinformatics analysis and Western blots. ACA and DTP developed and characterized Pten haploinsufficiency mouse model. RAR developed and characterized Cacnalc G406R mouse model. AUC, CFC, and BAJ interpreted results and wrote the paper.

\section{Acknowledgements:}

Supported by NIH R01AG039521 and NIH R56MH115201 to BAJ, T32GM007288 to AUC, NIH S10RR027990 to TAN, and NIH R01MH108519 to DTP. Significant support for this work came from the Rose F. Kennedy Intellectual and Developmental Disabilities Research Center (IDDRC), which is funded through the center grant NIH U54HD090260. 


\section{Abstract}

Impaired synaptic function is a common phenotype in animal models for autism spectrum disorder (ASD), and ASD risk genes are enriched for synaptic function. Here we leverage the availability of multiple ASD mouse models exhibiting synaptic deficits and behavioral correlates of ASD and use quantitative mass spectrometry with isobaric tandem mass tagging (TMT) to compare the hippocampal synaptic proteomes from 7 mouse models. We identified common altered cellular and molecular pathways at the synapse, including changes in Rho family small GTPase signaling, suggesting that it may be a point of convergence in ASD. Comparative analyses also revealed clusters of synaptic profiles, with similarities observed among models for Fragile X syndrome (Fmrl knockout), PTEN hamartoma tumor syndrome (Pten haploinsufficiency), and the BTBR+ model of idiopathic ASD. Opposing changes were found in models for cortical dysplasia focal epilepsy syndrome (Cntnap 2 knockout), Phelan McDermid syndrome (Shank3 InsG3680), Timothy syndrome (Cacnalc G406R), and ANKS1B syndrome (Anks lb haploinsufficiency), which were similar to each other. We propose that these clusters of synaptic profiles form the basis for molecular subtypes that explain genetic heterogeneity in ASD despite a common clinical diagnosis. Drawn from an internally controlled survey of the synaptic proteome across animal models, our findings support the notion that synaptic dysfunction in the hippocampus is a shared mechanism of disease in ASD, and that Rho GTPase signaling may be an important pathway leading to disease phenotypes in autism.

\section{Introduction}

Autism spectrum disorder (ASD) is a neurodevelopmental disorder characterized by socialcommunication deficits and restrictive and repetitive behaviors. Although the specific cause of ASD is unknown, autism is highly heritable, with a monozygotic twin concordance rate of $40-80 \%$ (Gaugler et al. 2014). The genetic architecture of ASD is extraordinarily complex, with common inherited variants and rare de novo mutations working together to confer genetic risk (Weiner et al. 2017). This polygenic etiology presents challenges for elucidating the molecular pathogenesis of autism. However, ASDrelated syndromes with defined genetic causes for autistic phenotypes present the best opportunities for elucidating the underlying mechanisms of ASD and identifying possible therapeutic targets (Sztainberg and Zoghbi 2016). These monogenic syndromes include Fragile X syndrome (FMRI), Rett syndrome (MECP2), PTEN hamartoma tumor syndrome (PTEN), tuberous sclerosis complex (TSC1/TSC2), Phelan McDermid syndrome (SHANK3), cortical dysplasia focal epilepsy syndrome (CNTNAP2) and Timothy syndrome (CACNAIC). Animal models of these syndromes have proven essential for studying the underlying neuropathology of ASD, especially changes in the complex processes of mammalian brain development and function.

Studies in rodents have shown that ASD risk genes converge on transcription regulation, protein homeostasis, and synaptic structure and function (Ruzzo et al. 2019; Pinto et al. 2014; De Rubeis et al. 2014). Accordingly, mice demonstrating the loss of Fmr1, Mecp2, Pten, Tsc1/Tsc2, Shank genes, or the Nrxn and Nlgn families all demonstrate changes in synaptic excitability or plasticity, and most also show altered dendritic growth or spine dynamics (Verma et al. 2019; Varghese et al. 2017; Hulbert and Jiang 2016; Huang, Chen, and Page 2016). Non-syndromic ASD models, such as those induced by valproic acid or maternal immune activation, also reveal structural and functional synaptic deficits, showing that environmental factors can lead to similar synaptic phenotypes (Andoh et al. 2019; Cellot et al. 2016; Li et al. 2018; Martin and Manzoni 2014; Patrich et al. 2016; Sui and Chen 2012; Wang et al. 2018). We recently developed a mouse model for ANKS1B haploinsufficiency, a rare genetic syndrome of ASD and other neurodevelopmental disorders caused by loss of the ANKSIB gene (Carbonell et al. 2019). $A N K S 1 B$ was previously identified in ASD risk gene networks (Li et al. 2014), and we found that its product AIDA-1 regulates activity-induced protein synthesis (Jordan et al. 2007), hippocampal synaptic plasticity (Tindi et al. 2015), and NMDA receptor subunit composition (Tindi, et al. 2015; Carbonell, et 
al. 2019). AIDA-1 is a core protein of the postsynaptic density and interacts with PSD95 in a complex that contains other factors associated with neurodevelopmental disorders, including Grin2b, Syngap1, and Nlgns (Carbonell, et al. 2019; Kaizuka and Takumi 2018). These findings support the idea that molecular mechanisms regulating synaptic function underlie ASD pathobiology (Bourgeron 2015; Zoghbi and Bear 2012).

Despite the heterogenous genetic architecture of autism and a complex etiology with contributions from environmental factors, ASD is diagnosed by distinct clinical criteria. Therefore, convergent cellular processes at the circuit, synaptic, or molecular level could underlie these shared behavioral phenotypes (Sestan and State 2018). In seeking convergent mechanisms among syndromic and non-syndromic forms of autism, comparative studies often narrowly focus on selected behaviors, specific synaptic phenomenology, or shared responses to preclinical pharmacological interventions (Schoen et al. 2019; Heise et al. 2018; Barnes et al. 2015). While broader comparisons have been made using transcriptomic analyses (Hernandez et al. 2020; Fores-Martos et al. 2019; Quesnel-Vallieres et al. 2019), these changes may not reflect mechanisms of disease due to multiple downstream levels of regulation such as protein translation, degradation, and transport (Vogel and Marcotte 2012). Proteomic approaches can therefore yield dramatically different results from transcriptomic profiles, as in a mouse model of Rett syndrome (Pacheco et al. 2017), and is particularly important when risk factors primarily regulate protein translation $(F m r 1, T s c 1 / T s c 2$, Pten) or degradation (Ube3a) (Louros and Osterweil 2016). ASD models in which synaptic scaffolding and membrane localization are altered (Shank3, $\mathrm{BTBR}+$ ) can also be investigated at the proteomic level, especially when the synaptic compartments and complexes are isolated by fractionation or immunoprecipitation (Reim et al. 2017; Lee et al. 2017; Murtaza, Uy, and Singh 2020; Brown et al. 2018). Indeed, analysis of postmortem brain tissue from ASD patients showed that some transcriptomic changes were not observed in cortical or cerebellar proteomes. However, changes in synaptic proteins predicted by ASD risk genes and animal models were confirmed (Abraham et al. 2019).

Here we compare the postsynaptic proteomes of seven mouse models for autism in which synaptic deficits have been described, with an emphasis on models of ASD-related syndromes: Fragile X syndrome (Fmrl -/Y), PTEN hamartoma tumor syndrome (Pten +/-), cortical dysplasia focal epilepsy syndrome (Cntnap2 -/-), Phelan-McDermid syndrome (Shank3 InsG3680), Timothy syndrome (Cacnalc G406R), ANKS1B syndrome (Anks $1 b+/-)$, and the BTBR+ inbred strain. These models have

demonstrated face validity for autism, displaying hallmark behavioral correlates of ASD including social interaction deficits and restrictive behaviors (Kazdoba, Leach, and Crawley 2016; Zhou et al. 2016; Kabitzke et al. 2018; Carbonell, et al. 2019). In each model, we find evidence for upstream regulators that alter synaptic composition with predicted functional effects consistent with clinical phenotypes in ASD and individual syndromes. Mouse models can be clustered according to similarities and differences in upstream regulators, functional effects, and canonical pathways predicted by changes in their synaptic proteomes. Notably, we identified two groups of models with shared changes in the synaptic proteome, which may represent molecular subtypes of ASD. Proteins involved in Rho family GTPase signaling are commonly altered, especially the Rac signaling pathway. Measuring the expression of Rho GTPases in these models yielded new insights into differential regulation of Rho GTPase activity at the synapse. Appreciation of convergent synaptic changes underlying ASD is critical for defining pathogenic mechanisms and prioritizing treatments that can have broad efficacy (Sestan and State 2018). Our results suggest that targeting Rho GTPases may lead to the design of effective therapeutic interventions for diverse forms of autism spectrum disorder.

\section{Materials and Methods}

\subsection{Mouse tissue and fractionation}


Animals from the Fmrl knockout (stock \#003025, MGI:1857169), Cntnap2 knockout (stock \#017482, MGI: 2677631), and Shank3 InsG3680 mutant (stock \#028778, MGI: 5775620) mouse models; and the BTBR+ (stock \#002282), B6129SF2/J (stock \#101045), and C57BL/6J (stock \#000664) mouse strains were purchased from the Jackson Laboratory. Mice with Pten haploinsufficiency (MGI:2151804) and wild-type mice on the C57BL/6J background were obtained from the Page lab at the Scripps Research Institute Florida. Mice with the Cacnalc G406R mutation (MGI:5296904) and wild-type mice on the $\mathrm{C} 57 \mathrm{BL} / 6 \mathrm{~J}$ background were obtained from the Rasmusson lab at the University at Buffalo. Heterozygotes from the Anks $1 b$ conditional knockout line (stock \#035048, MGI:5779292) (Tindi, et al. 2015) and wild-type mice from the Nestin-cre transgenic line (stock \#003771, MGI:2176173) were bred in house (Carbonell, et al. 2019). Mice from this line expressing the Nestincre transgene were genotyped for the Anks $1 b^{w t}$ allele (forward: 5'-CACCCACAGCTCCATAGACAG3', reverse: 5'-GCACCTATTCCCTTCACCCTG-3') and Anks $1 b^{f l}$ allele (forward: 5'AGTTGCCAGCCATCTGTTGT-3', reverse: 5'-GGGTTCCGGATCAGCTTGAT-3'). For each proteomics experiment, we pooled hippocampi from 2 male mice of each genotype at 6-10 weeks of age. Postsynaptic density (PSD) enriched fractions were isolated from hippocampal tissue using sucrose density centrifugation and detergent extraction. To obtain sufficient material from hippocampal PSD fractionation of 2 animals, we used a modified protocol with a single incubation in $0.5 \%$ Triton-X100 as previously done (Tindi, et al. 2015).

\subsection{Western blot}

SDS-PAGE and Western blot were performed under standard conditions using the LI-COR system with the following antibodies: rabbit anti-Rac1 1:1000 (Proteintech \#24702-1-AP), rabbit antiRhoA 1:1000 (ABclonal), rabbit anti-Cdc42 (ABclonal), anti-Arf1 1:1000 (clone ARFS 1A9/5, Santa Cruz \#53168), rabbit anti-Arf1 1:1000 (Proteintech \#20226-1-AP), mouse anti-PSD95 1:1000 (NeuroMab), and rat anti-tubulin 1:1000 (Cell Signaling Tech). Statistical analysis for Western blot was performed in JMP 14 (SAS) as in Supplementary Table 6Error! Reference source not found..

\subsection{Tandem mass tag labeling of peptides}

For each experiment, tryptic peptide pools generated from 10 hippocampal PSD-enriched samples (15 $\mu \mathrm{g}$ protein each for Experiment 1, $20 \mu \mathrm{g}$ protein each for Experiment 2) were reacted with unique isobaric labels within a tandem mass tags (TMT) set (Thompson et al. 2003) and analyzed together using high-resolution (Q Exactive HF) mass spectrometry (Carbonell, et al. 2019; Klein et al. 2019). Each sample was electrophoresed briefly (dye front $5 \mathrm{~mm}$ ) into a 4-12\% SDS-PAGE gel. The gel was washed $3 \mathrm{x}$ in $\mathrm{ddH}_{2} \mathrm{O}$ for 15 min each and visualized by staining overnight with GelCode ${ }^{\circledR}$ Coomassie blue reagent (Pierce). Stacked protein bands were excised from the gel, reduced with DTT, and alkylated with iodoacetamide. In-gel digestion was performed using $5 \mathrm{ng} / \mu \mathrm{L}$ mass spectrometrygrade trypsin (Trypsin Gold, Promega) in $50 \mathrm{mM} \mathrm{NH}_{4} \mathrm{HCO}_{3}$ digestion buffer. The resulting peptides were desalted using a Stage Tip manually packed with Empora C18 High Performance Extraction Disks (3M) (Rappsilber, Mann, and Ishihama 2007) and eluted peptide solutions were dried under vacuum. Peptides were then resuspended in $18 \mu \mathrm{L}$ acetonitrile (ACN), and $57 \mu \mathrm{L}$ of $0.2 \mathrm{M}$ HEPES pH 8.5 was added to each sample. TMT10-plex amine reactive reagents (Thermo Fisher, $5 \mathrm{mg}$ per vial) were resuspended in $1024 \mu \mathrm{L}$ anhydrous acetonitrile and $25 \mu \mathrm{L}$ of reagent was added to each sample (TMT label: peptide $[\mathrm{w} / \mathrm{w}]=12: 1)$ and mixed briefly by vortexing. The mixture was incubated at RT for $1 \mathrm{hr}$, quenched by the addition of $10 \mu \mathrm{L} 5 \%$ hydroxylamine for $15 \mathrm{~min}$, and acidified by the addition of $10 \mu \mathrm{L}$ $10 \%$ formic acid. A $5-\mu \mathrm{L}$ aliquot from each reaction was desalted on a StageTip, analyzed by LCMS/MS with a Q Exactive Orbitrap HF (high field), and the resulting spectra searched with MaxQuant using its corresponding TMT label as variable modifications on N-terminus and lysine. The percentage of peptides with either N-terminal or lysine TMT labels was calculated, indicating the labeling efficiency for each channel. Labeling efficiency was $95 \%$ or greater for each channel. To ensure that 
equal amounts of labeled peptides from each channel were mixed together, a two-step mixing strategy was employed: in the first step, an identical $\sim 1 \mu \mathrm{L}$ volume of peptides from each channel was mixed and analyzed, and the value of the median ratio (median of the ratios of all peptide intensities of one channel over their corresponding peptide average intensities of all channels) for each channel was determined as the correction factor. In the second step, the rest of the peptides were mixed by adjusting their volume using the correction factors. In this way, median ratios ranging from 0.97 to 1.02 were achieved as previously reported (Erdjument-Bromage, Huang, and Neubert 2018). The final mixture of reaction products from 10 TMT channels were desalted on a Sep-Pak tC18 1mL Vac Cartridge (Waters, \#WAT03820). Eluted peptides were dried by vacuum centrifugation and stored at $-20^{\circ} \mathrm{C}$.

\subsection{Hydrophilic Interaction Liquid Chromatography (HILIC) Fractionation of Peptides}

We fractionated PSD samples by offline HILIC to increase depth of coverage and decrease ratio compression due to co-fragmenting peptides (Huang et al. 2017). Final TMT mix was dissolved in $90 \%$ acetonitrile with $0.1 \%$ TFA and peptide separation was carried out on an Agilent pump equipped with a TSK gel amide- 80 column ( $4.6 \mathrm{~mm}$ ID, $25 \mathrm{~cm}$ long) from TOSOH Bioscience, LLC, PA, USA). A gradient of $90 \%$ acetonitrile with $0.1 \%$ TFA was introduced over 65 min., and a fraction was collected every 2 minutes. Concatenated pools of peptides (10 pools) were finally created by pooling non-adjacent peptide fractions; about $10 \%$ of each pool was used for LC-MS/MS analysis.

\subsection{Liquid chromatography-tandem mass spectrometry}

Online chromatography was performed with a Thermo Easy nLC 1000 ultrahigh-pressure UPLC system (Thermo Fisher) coupled online to a Q Exactive HF with a NanoFlex source (Thermo Fisher). Analytical columns ( $\sim 23 \mathrm{~cm}$ long and $75 \mu \mathrm{m}$ inner diameter) were packed in house with ReproSil-Pur C18 AQ $3 \mu \mathrm{M}$ reversed-phase resin (Dr. Maisch GmbH, Ammerbuch-Entringen). The analytical column was placed in a column heater (Sonation $\mathrm{GmbH}$, Biberach) regulated to a temperature of $45^{\circ} \mathrm{C}$. The TMT peptide mixture was loaded onto the analytical column with buffer A ( $0.1 \%$ formic acid) at a maximum back-pressure of 300 bar. Peptides were eluted with a 2 -step gradient of $3 \%$ to $40 \%$ buffer B ( $100 \% \mathrm{ACN}$ and $0.1 \%$ formic acid) in $180 \mathrm{~min}$ and $40 \%$ to $90 \% \mathrm{~B}$ in $20 \mathrm{~min}$, at a flow rate of 250 $\mathrm{nL} / \mathrm{min}$ over $200 \mathrm{~min}$ using a 1D online LC-MS2 data-dependent analysis (DDA) method as follows: MS data were acquired using a data-dependent top- 10 method, dynamically choosing the most abundant not-yet-sequenced precursor ions from the survey scans (300-1750 Th). Peptide fragmentation was performed via higher energy collisional dissociation with a target value of $1 \times 10^{5}$ ions determined with predictive automatic gain control. Isolation of precursors was performed with a window of $1 \mathrm{Th}$. Survey scans were acquired at a resolution of 120,000 at $\mathrm{m} / \mathrm{z} 200$. Resolution for HCD spectra was set to 60,000 at $m / z 200$ with a maximum ion injection time of $128 \mathrm{~ms}$. The normalized collision energy was 35 . The underfill ratio specifying the minimum percentage of the target ion value likely to be reached at the maximum fill time was defined as $0.1 \%$. Precursor ions with single, unassigned, or seven and higher charge states were excluded from fragmentation selection. Dynamic exclusion time was set at $30 \mathrm{sec}$. Each of the TMT 10-plex samples was analyzed in triplicate.

All data were analyzed with the MaxQuant proteomics data analysis workflow (version 1.5.5.7) with the Andromeda search engine (Cox et al. 2011; Tyanova, Temu, and Cox 2016). The type of the group specific analysis was set to Reporter ion MS2 with 10plex TMT as isobaric labels for Q Exactive HF MS2 data. Reporter ion mass tolerance was set to $0.01 \mathrm{Da}$, with activated Precursor Intensity Fraction (PIF) value set at 0.75 . False discovery rate was set to $1 \%$ for protein, peptide spectrum match, and site decoy fraction levels. Peptides were required to have a minimum length of eight amino acids and a maximum mass of 4,600 Da. MaxQuant was used to score fragmentation scans for identification based on a search with an allowed mass deviation of the precursor ion of up to $4.5 \mathrm{ppm}$ after timedependent mass calibration. The allowed fragment mass deviation was $20 \mathrm{ppm}$. MS2 spectra were used by Andromeda within MaxQuant to search the Uniprot mouse database (01092015; 16,699 entries) 
combined with 262 common contaminants. Enzyme specificity was set as C-terminal to arginine and lysine, and a maximum of two missed cleavages were allowed. Carbamidomethylation of cysteine was set as a fixed modification and N-terminal protein acetylation, deamidated (N, Q) and oxidation (M) as variable modifications. The reporter ion intensities were defined as intensities multiplied by injection time (to obtain the total signal) for each isobaric labeling channel summed over all MS/MS spectra matching to the protein group as previously validated (Tyanova, Temu, and Cox 2016). Following MaxQuant analysis, the protein and peptide .txt files were imported into Perseus (version 1.5.6.0) software which was used for statistical analysis of all the proteins identified.

\subsection{Bioinformatics analysis}

For each mouse model of autism, fold-change of each protein was calculated by dividing relative abundance of each sample by the abundance in the appropriate control sample. For the Fmr 1, Pten, Cntnap2, Cacnalc, and BTBR+ models, we used the average of 2 samples of C57BL/6J mice as the control value. For Shank3 mice on the B6129SF2/J background, we used a sample of wild-type mice from the same colony as the control value. For the Anks lb Het mice on the Nestin-cre C57BL/6J background, we used wild-type littermates on the Nestin-cre C57BL/6J background as the control value. Of the proteins quantified in all samples, we filtered duplicate genes for the protein IDs with highest number of unique peptides, highest sequence coverage, and lowest Q-values, yielding the highest intensity and scores. We considered the proteins identified by $>2$ peptides in Experiment 1 or $>9$ peptides in Experiment 2 as the hippocampal PSD proteome, to obtain a reliable fold change for each protein. We used this list of 788 proteins (Experiment 1) or 830 proteins (Experiment 2) as input for multiple proteins in StringDB under the species Mus musculus. Raw data for gene ontology (GO) enrichments were generated in StringDB (Szklarczyk et al. 2015).

Functional annotation, activation prediction, and regulatory network construction was performed for each mouse model using Ingenuity Pathway Analysis (IPA, QIAGEN Bioinformatics, version 52912811). Fold-change values for each protein in the PSD proteome was used as input for a Core Analysis in IPA using the following default settings: Expression Analysis; General Settings = Ingenuity Knowledge Base (Genes Only), Direct Relationships; Networks = Interaction networks, Include endogenous chemicals; Node Types $=$ All; Data Sources $=$ All; Confidence $=$ Experimentally Observed; Species $=$ All; Tissues $\&$ Cell Lines $=$ All; Mutations $=$ All . For each model, Regulator Effects networks were generated to yield regulators of Type $=$ All, diseases and functions of Category $=$ All, with a $p$ value cutoff of $<0.01$ and $z$-score cutoff of $>|2|$. To score similarity between models overall and in each domain (Upstream Regulators, Downstream Effects, and Canonical Pathways), Analysis Match was used. In Analysis Match, activity signatures for each Core Analysis are generated by taking the top 50 (Upstream Regulators and Downstream Effects) or 10 (Canonical Pathways) entities that are activated $(z$-score $>2)$ and inhibited $(z$-score $<-2)$ in each domain. Similarity $z$-scores between Core Analyses are defined using the following formula, where $N$ is the total number of overlapping entities in each analysis, $N_{+}$is the number of correct matches, and $N_{-}$the number of incorrect matches:

$$
\text { raw } z \text {-score }=\left(N_{+}-N_{-}\right) /(\sqrt{ } N)
$$

The raw $z$-score is divided by a hypothetical perfect match $\left(N_{+}=N \leq 100, N_{-}=0\right)$ and multiplied by $100 \%$ to obtain a normalized $z$-score, where a score of 100 is a perfect match to itself. Raw and normalized $z$-scores are negative when $N_{-}>N_{+}$, yielding an opposite activation signature. To generate overall $p$-value scores, the $-\log _{10}$ of the $p$-values (maximum value of 50 ) were calculated for each domain, and expressed as a percentage of the maximum possible - $\log _{10} p$ (a perfect match to itself). To compare models, the Core Analysis of each model were used as input for a Comparison Analysis in IPA. Hierarchical analysis was used to cluster annotations in Upstream Analysis, Downstream Effects, and Canonical Pathways, and to cluster models for similarity relationships. 


\subsection{TMT-MS analyses of postsynaptic density fractions from mouse models of autism.}

To investigate the synaptic proteome in autism, we selected 7 mouse models: Fmrl knockout (Fmr1 KO) (Consortium 1994), Pten haploinsufficiency (Pten Het) (Clipperton-Allen and Page 2015; Clipperton-Allen and Page 2014), Cntnap2 knockout (Cntnap2 KO) (Penagarikano et al. 2011), Shank3 frameshift mutation InsG3680 (Shank3*) (Zhou, et al. 2016), Timothy syndrome mutation Cacnalc G406R (Cacna 1c*) (Bader et al. 2011), Anks lb haploinsufficiency (Anks1b Het) (Carbonell, et al. 2019), and the BTBR+ inbred strain (McFarlane et al. 2008). All selected models display abnormal behaviors in domains relevant to ASD, including social approach and interaction, stereotyped movements, learning and memory, and sensorimotor function. These models have also been used to illustrate synaptic dysfunction, including altered synapse formation, excitatory/inhibitory balance, synaptic plasticity, and glutamatergic signaling (Hulbert and Jiang 2016; Varghese, et al. 2017; Bagni and Zukin 2019; Carbonell, et al. 2019). To analyze changes in the synaptic proteome for each mouse model of autism, we isolated the hippocampus and used sucrose density-based centrifugation to yield postsynaptic density (PSD) enriched fractions. Western blot of these samples demonstrated enrichment for the marker PSD95 in each PSD fraction compared to total hippocampal lysate from each model (Figure 1A). We then processed the samples for tandem-mass-tag mass spectrometry (TMT-MS) to simultaneously analyze the synaptic proteome in each ASD model with other models and their appropriate control samples (Figure 1B). This method reduces the variability induced by mass spectrometry and allows comparison of protein abundance from peptides reliably quantified with a minimum of 2 peptides, across all samples (Error! Reference source not found.). After peptide identification and filtering for proteins by number of peptides quantified, we obtained a synaptic proteome of 788 proteins for Experiment 1 (Supplementary Table 1) and 830 proteins for Experiment 2 (Supplementary Table 2). This number is consistent with previous studies showing 984 PSD proteins in mice, 748 in humans, and 546 consensus proteins between them (Bayes et al. 2012). As expected, gene ontology (GO) analysis of the synaptic proteomes we identified in STRING (Szklarczyk et al. 2019) revealed significant enrichment for synaptic proteins and similar enrichments between experiments (Figure 1C). As a functional readout, the synaptic proteomes were also enriched for reaction pathways involved in synaptic formation and transmission (Figure 1DError! Reference source not found.). Consistent with the organized structure and specialized function of the PSD, biological processes related to cellular organization and neural development were enriched (Supplementary Table 3). Comparing the synaptic proteomes to the 1,104 synaptic proteins annotated in the SynGO database (Koopmans et al. 2019), 336 synaptic proteins were identified in Experiment 1 (Fisher's exact test, $p=2.09 \mathrm{e}-188$ ) and 295 synaptic proteins were found in Experiment 2 (Fisher's exact test, $p=5.23 \mathrm{e}-142$ ) (SynGO geneset analysis, https://syngoportal.org). These results validate the efficient detection of synaptic proteins through TMT-MS.

\subsection{Predicted effects drive synaptic similarities among ASD mouse models}

To obtain a fold-change of the synaptic proteins for each ASD model, we used C57BL/6J mice as controls, except for the Shank3* and Anks1b Het models, for which we used wild-type animals from the same colony on the B6129SF2/J and Nestin-cre C57BL/6J backgrounds, respectively. For each mouse model, we performed a Core Analysis of fold-changes in the synaptic proteome in Ingenuity Pathway Analysis (IPA, QIAGEN Bioinformatics) to score the Diseases and Functions (Supplementary Table 4), Upstream Regulators (Supplementary Table 5), and Canonical Pathways (Supplementary Table 5) significantly enriched ( $p$-values) and altered ( $z$-scores) in the synaptic proteomes from Experiment 1 and Experiment 2 (Kramer et al. 2014). To test whether ASD mouse models display shared changes in their synaptic proteomes, we quantitatively compared the results of the Core Analysis from each model using Analysis Match in IPA (Figure 2A-B). To obtain overall similarity scores, IPA incorporates activation $z$-scores from Upstream Regulators, Downstream Effects (Diseases and Functions), and Canonical Pathways from each Core Analysis into activation patterns (activity 
signatures) that can be compared across analyses (see Materials and Methods). Similarity $z$-scores reflect the percentage of maximum similarity to a given model (out of $100 \%$, a perfect match to itself).

Overall similarity $z$-scores and $p$-value scores (out of 100) from Experiment 1, where we tested 6 ASD models, are given in Figure 2A. For the Fmrl KO mouse model, the highest similarity $z$-score was with Pten Het mice $(z$-score 55.0). The Cacnalc* $(z$-score -67.2) and Shank3* $(z$-score -50.6) were the most dissimilar models to the Fmr1 KO, with significant changes in the opposite direction to those observed in the Fmr1 KO mouse indicated by high negative $z$-scores. Similarly, the Pten Het model was most similar to Fmr1 KO, and most dissimilar to the Cacnalc* and Shank3* mice. For the BTBR+ strain, the Cntnap2 KO ( $z$-score 45.2) and Cacna1 $\mathrm{c}^{*}(z$-score 48.2) were both similar and no other models were substantially dissimilar. For the Cntnap2 KO model, the BTBR+ strain $(z$-score 42.3$)$ and Cacna 1 $\mathrm{c}^{*}$ model ( $z$-score 38.1) were most similar and the Fmr1 KO model most dissimilar ( $z$-score 33.5). For the Shank3* model, the Cacna 1c* model was most similar ( $z$-score 44.6), with Fmr1 KO (zscore -60.6) and Pten Het ( $z$-score -32.2) models showing opposite activation signatures. For the Cacna 1 ${ }^{*}$ model, activation patterns were strongly opposite in direction to Fmr1 KO (z-score -66.48) and Pten Het ( $z$-score -64.5), while somewhat similar to other models (BTBR $z$-score 43.2, Shank $3 * z$ score 35.5, Cntnap2 KO $z$-score 33.2). In the overall similarity $z$-scores, a pattern emerged of consistent agreement between Fmr1 KO and Pten Het models, intermediate similarity of BTBR+ and Cntnap2 KO mice to other models, and dissimilarity of Shank3* and Cacnalc* models to Fmr1 KO and Pten Het (Figure 2A).

To test for reproducibility of findings, we performed a second experiment (Experiment 2), where we once again compared the Fmr1 KO and BTBR+ strains, which are widely studied mouse models of monogenic and idiopathic ASD, to Pten Het and Cntnap2 KO mice, which showed the most similarity to these models in Experiment 1. This time, we included biological replicates of our Anks1b Het mouse model (Figure 2B). Similar to Experiment 1, the Pten Het model was most similar to Fmrl (z-score 40.1), although Fmr1 KO was also similar to BTBR+ (z-score 72.4) and Cntnap2 KO (z-score 62.8) models. Compared to Experiment 1, overall similarity among the replicated models was greater in Experiment 2, with BTBR+ similar to Cntnap2 KO (z-score 72.6) and to other models (Fmr1 KO $z$-score 75.1, Pten Het $z$-score 40.8). Cntnap2 KO was also similar to BTBR+ (z-score 70.5) and Fmr1 KO (zscore 62.0), although not similar to Pten Het (z-score 0.6). Strikingly, the Anks 1b Het samples were most consistently similar to Cntnap2 KO (Anks1b Het1 $z$-score 70.9, Anks1b Het2 $z$-score 61.1) and had opposite activation signatures to Pten Het (Anks1b Het1 $z$-score -7.9, Anks1b Het2 $z$-score -57.3). Similarities to Fmr1 KO and BTBR+ were not consistent but tended to be positive (Figure 2B). Biological replicates for the Anks1b Het model were highly similar to each other, demonstrating internal consistency and thus validating our TMT methodology and IPA-based predictions from proteomics measurements (Anks1b Het1 to Het2 $z$-score 65.0, Het2 to Het1 $z$-score 60.6). For all similarity $z$-scores, $p$-values for overlap of commonly activated and inhibited entities were calculated in IPA using Fisher's exact test ( $p<0.01$ for all comparisons).

The overall similarity $z$-scores incorporate activation patterns from predicted Upstream Regulators, Downstream Effects, and Canonical Pathways. For each domain of comparison, the trends for similar or opposite activation between ASD mouse models were largely consistent. When comparing Upstream Regulators, activation signatures in Fmr1 KO and Pten Het models were similar to each other and dissimilar to Shank3 and Cacnalc* by Analysis Match and cluster analysis (Figure 2C). While similar to Fmr1 KO and Pten Het in both Experiment 1 and 2 (Figure 2C), the BTBR+ strain also showed similarities to the Cacna1c* model ( $z$-score 40.8). Experiment 2 showed similar activation patterns across models, except for the Pten Het model, which showed limited similarity to Cntnap2 KO ( $z$-score 10.3) and Anks1b Het (Het1 $z$-score 18.7, Het2 $z$-score -22.9). In Experiment 1, predicted upstream regulators with the largest magnitude of activation or inhibition included Mlxipl, Myc, Kdm5a, and Rest. Variants in Mlxipl are associated with autism in Williams-Beuren syndrome (Codina-Sola et al. 2019). Activation $z$-scores for Mlxipl and Myc were driven by changes in ribosomal and 
mitochondrial proteins regulated by Myc and Ctnnb1 (Supplementary Table 5). Kdm5a is part of a family of histone demethylases, of which several members have been implicated in intellectual disability (Vallianatos et al. 2018; Zamurrad et al. 2018). While Kdm5a activation was inconsistent in Experiment 1 (Figure 2C), Experiment 2 showed Kdm5a inhibition across Pten Het, Fmr1 KO, BTBR+, Cntnap2 KO, and Anks1b Het models (Figure 2D). Across experiments, inhibition of Rest (RE1-silencing transcription factor) and activation of Tlx3 was predicted in Fmr1 KO and Pten Het, while the opposite was seen in Cntnap2 KO, Cacna1 c*, and Anks1b Het models (Figure 2C-D). Mecp2 was predicted to be activated or unchanged in Fmr1 KO, Pten Het, and BTBR+, but inhibited in the other 4 models (Figure 2C-D).

\subsection{Altered synaptic composition yields networks of functional effects}

After comparing Upstream Regulators, we compared activation signatures for Downstream Effects on diseases and functions enriched in the synaptic proteomes. Like Upstream Regulators, Downstream Effects are predicted in IPA from an updated knowledge base drawn from the literature (Kramer, et al. 2014). Results were largely consistent with overall similarity trends, with significant similarities between Fmr1 KO and Pten Het by Analysis Match and cluster analysis (Figure 3A-B). However, there were fewer differences between BTBR+ and the other models than overall or in Upstream Regulators, and Shank3* showed activation patterns intermediate between the Fmr1 KO/Pten Het and BTBR+/Cntnap2/Cacna1 $\mathrm{c}^{*}$ clusters (Figure 3A). In Experiment 2, Anks1b Het mice showed similar activation signatures to Cntnap2 KO (Anks1b Het1 $z$-score 55.3, Anks $1 \mathrm{~b}$ Het2 $z$-score 57.1) and opposing activation to the Pten Het and Fmrl KO models by Analysis Match and cluster analysis (Figure 3B). Across models, the most divergent functional effects were on cellular structure, including cellular protrusions, microtubule dynamics, and cytoskeleton regulation for neuronal development, which were activated for Fmr1 KO and Pten Het and inhibited for other models (Figure 3A-B). Opposing effects on disease were evident in movement and seizure disorders, which were predicted to be downregulated in Fmr1 KO and Pten Het mice (Figure 3A-B), while effects on cognitive impairment and emotional behavior did not strongly differ across models (Figure 3A-B).

We next focused on IPA results for Regulatory Effects, which links Upstream Regulators (genes, RNAs, and proteins, Figure 2C-D) to Downstream Effects (diseases and disorders, physiological systems, cellular and molecular functions, Figure 3A-B) through observed changes in the synaptic proteome. Top-scoring networks for each model display consistent directionality (score $>0$ ) and yield unified, functional representations of altered synaptic proteins in each model with implied upstream causes and predicted downstream effects from the IPA knowledge base. For the Fmr1 KO model, activated Tlx3, Erg, and Fev regulate synaptic targets that contribute to a range of neurodevelopmental functions, including synaptic development, motor coordination, cognitive impairment, and hyperactivity (Experiment 1, Figure 4A). A larger network driven by inhibited Kdm5a and Nr4a1, among others, predicts altered energy metabolism and congenital neurological disorder (Experiment 2, Figure 4B). These trends are consistent across experiments, with inhibited Kdm5a predicted in Experiment 1 (Error! Reference source not found.A) and activated Tlx3 in Experiment 2 (Error! Reference source not found.B). Similarly, the Pten Het model also showed predicted activation of Tlx3 and inhibition of $\mathrm{Kdm} 5 \mathrm{a}$, predicting increased neurotransmission and neuronal movement (Experiment 2, Figure 4C). Tlx 3 activation of neurotransmission was also predicted as a top network in Experiment 1 (Error! Reference source not found.C). Inhibition of Rest and activation of Mecp2 were predicted to activate endocytosis and neurite outgrowth, as well as proteins involved in long-term depression of the synapse (Experiment 2, Figure 4D). Similar to the Pten Het model, the BTBR+ strain shows inhibition of Rest, predicting increased vesicle endocytosis and transport (Experiment 2, Figure 4E). Additionally, inhibition of Neurod1 promotes organismal death while reducing long-term potentiation and memory (Experiment 2, Figure 4F). However, BTBR+ strain diverges from the Fmr1 KO and Pten Het models in 
the predicted inhibition of Fev, leading to reduced neurotransmission downstream (Error! Reference source not found.C).

In contrast to Fmr1 KO and Pten Het, the Cntnap2 KO model showed inhibited expression of genes controlled by Tlx3 as the top network in both experiments, predicting reduced neurotransmission and hyperactive behavior (Figure 5A, Error! Reference source not found.E). Another regulatory network, driven by inhibited Mecp2 and Zpf3612, was predicted to reduce neurite growth and vesicle quantity while promoting seizures (Experiment 1, Figure 5B). Downward changes of synaptic channels and receptors is consistent with activated Rest, which was predicted to reduce vesicle transport, synaptic plasticity, and cognition (Experiment 1, Figure 5C). In the Shank3* model, Zfp3612 was also inhibited in a network with activated Calr, predicting neurodegeneration and altered protein metabolism (Figure 5D). Although changes in the Shank3* synapse were milder than in other models, inhibited Arnt and Tfe 3 predicted motor dysfunction and movement disorders in another top network (Error! Reference source not found.F). In the Cacnalc* model, the top regulatory network shows downregulation of both Fev and Tlx3, predicting inhibition of neural development and synaptic transmission and promotion of seizures and motor dysfunction (Figure 5E). As in the BTBR+ strain, inhibition of Neurod1 predicts reduced synaptic plasticity and memory (Figure 5F). However, an extensive network driven by activated Rest and $\mathrm{Htt}$ and inhibited Nfe212 promotes heart failure and impaired synaptic depression, in contrast to the Fmr1, Pten Het, and BTBR+ models (Error! Reference source not found.G). In the Anks $1 b$ Het model, Erg inhibition in both biological replicates, along with Nfe2l2 activation, predicted the downregulation of cell motility, neuronal apoptosis, and brain formation (Figure 5G, Error! Reference source not found.H). Overall effects were mild, similar to the Shank3* model, but reduced social behavior and increased seizure activity were predicted by activated Hifla and inhibited Ptfla (Ankslb Het2, Figure 5H). Although Erg inhibition was in opposition to the Fmr1 KO, inhibited Kdm5a and Nr4a1 in the Anks $1 \mathrm{~b}$ Het were similar to the Fmr1 KO (Figure 4B) and other models in Experiment 2 (Figure 2D), predicting altered energy metabolism at the synapse (Error! Reference source not found.I). In summary, networks of Regulatory Effects in each model show that common upstream regulators (Rest, Tlx3, Mecp2, Kdm5a) predict downstream effects on synaptic function and brain disorders.

\subsection{Synaptic changes predict altered Rho GTPase signaling across models}

To identify cellular processes commonly altered in mouse models of autism, we compared activation of Canonical Pathways in IPA. In this domain, the relationships between ASD models were less consistent than in Upstream Analysis and Downstream Effects. In both Experiment 1 and Experiment 2, Analysis Match of Canonical Pathways revealed that some comparisons did not yield a similarity score $(p>0.01)$, indicating that the relationship between them was neither significantly opposite nor similar (Kramer, et al. 2014). However, we did find similarity in the activation of molecular pathways between Fmr1 KO and Pten Het models, and among BTBR+, Cntnap2 KO, and Cacna1c* models in Experiment 1 (Figure 6A). In Experiment 2, we found that BTBR+, Cntnap2 KO, and Anks 1b Het models were similar to each other (Figure 6B). In both experiments, significant changes ( $z$-score $>$ |2|) in pathways related to Rho GTPases featured prominently, including Signaling by Rho Family GTPases, RhoGDI Signaling, Rac Signaling, RhoA Signaling, Cdc42 Signaling, and Regulation of Actin-based Motility by Rho (Figure 6A-B). Directionality was largely consistent among mouse models, predicting activated signaling by Rho GTPases and inhibited regulation by RhoGDI, with the exception of Cacnalc* and Anks1b Het models (Figure 6A-B). Rho GTPase signaling was among the most enriched signaling pathways in the synaptic proteomes by STRING analysis (Figure 1D). The Rho (Ras homology) GTPases are an essential family of small guanine nucleoside triphosphate (GTP) binding proteins that hydrolyze GTP to regulate numerous aspects of neuronal development and function (Niftullayev and Lamarche-Vane 2019; Zamboni et al. 2018b), including synaptic transmission and plasticity (Murakoshi, Wang, and Yasuda 2011; Hedrick and Yasuda 2017). 
Since Rho GTPases have crucial roles in synaptic function that have been investigated in both human-based experiments and mouse models of ASD (Guo, Yang, and Shi 2020), we prioritized these pathways for further study. In hippocampal PSD fractions, only the small GTPase Rac1 met peptide cutoff criteria for inclusion in the synaptic proteome for both experiments. Analysis of the Rac Signaling pathway for each ASD mouse model shows strong activation in the Fmr1 KO (z-scores 3.96 and 2.98), Pten Het (z-scores 3.13 and 3.44), and BTBR+strain (z-scores 1.04 and 2.52); weak activation in the Cntnap2 KO (z-scores 0.21 and 0.69$)$ and Shank3* model ( $z$-score 0.626$)$; and inhibition of the Rac pathway in the Cacnalc* (z-score -3.96) and Anks1b Het models ( $z$-score -0.69 and -2.98) (Table 1Error! Reference source not found.). In addition to Rac Signaling, RhoA and Cdc42 Signaling pathways displayed activation $z$-scores in a similar pattern: strong upregulation in Fmr1 KO, Pten Het, and BTBR+ strains, intermediate activation in Cntnap2 KO and Shank3*, and inhibition in Cacnalc* and Anks1b Het (Table 1). Depictions of the Rac Signaling pathway show that altered synaptic components of the pathway predicted activation in the Fmr1 KO (Experiment 1, Figure 7A) and BTBR+ models (Experiment 2, Figure 7B). In contrast, Rac Signaling was inhibited in the Cacna1c* (Figure 7C) and Anks $1 \mathrm{~b}$ models (Het2, Figure 7D). Overall, Rho-related signaling pathways showed opposing clusters of predicted activation (Fmr1 KO, Pten Het, BTBR+, Cntnap2 KO, Shank3*) and inhibition (Cacna1 c* and Anks1b Het).

\subsection{Rho GTPases are differentially expressed in autism mouse models}

For the mouse models of ASD showing significant upregulation of the Rac signaling pathway, with $z$-scores $>2$, Rac itself is upregulated (Rac in magenta, Figure 7A,B). To evaluate the synaptic expression of Rho family GTPases in mouse models for autism, we performed Western blots for Rac1, RhoA, and Cdc42 in synaptic fractions. Although we did not detect an immunoblot signal for RhoA and Cdc42 in PSD fractions using several antibodies, we were able to quantify Rac1 expression (Figure 8A). Consistent with the proteomics results showing strongest activation of the Rac signaling pathway, Rac 1 expression was increased in the Fmrl KO and Pten Het models. However, Racl was also increased the Anks $1 b$ Het and no difference was measured in the BTBR+ strain or other models (Figure 8B). To determine whether the upregulation of Rac1 was specific to the synaptic compartment, we compared Rac1 expression levels in total lysate among all models. In contrast to our findings in the PSD fraction, we found broad reduction in Rac1 expression across ASD mouse models, including the Fmr1 KO, Pten Het, BTBR+ and Shank3* models in which Rac pathway activation was predicted in IPA (Figure 8C). The Anks1b Het model, in which inhibition of Rac signaling was predicted, also showed reduction of Rac1 in total lysate. Notably, Rac1 expression was significantly increased in the Cacna1c* model, which showed the strongest inhibition of Rac signaling as predicted from the proteomic data (Figure 6A).

In general, Rac pathway activation predicted in IPA was correlated with increased Rac1 expression in the PSD (Fmr1 KO and Pten Het) and reduced Rac1 in total lysate (Fmr1 KO, Pten Het, BTBR+, Cntnap2 KO, and Shank3*), while strong inhibition of Rac signaling was associated with increased Rac1 expression in total lysate (Cacnalc*). To test whether other Rho GTPases display a similar correlation between activation and expression, we performed Western blots for RhoA and Cdc42 in total lysate. RhoA expression was reduced in the Fmr1 KO, Pten Het, and Shank3* mouse models (Figure 8C). In agreement with our findings of reduced Rac1 expression, these models shared a predicted activation for the RhoA signaling pathway: Fmr1 KO $z$-scores 3.00 and 1.26, Pten Het $z$-scores 3.40 and 3.41, and Shank3* $z$-score 1.80 (Table 1). However, the trend with RhoA was less consistent than Rac1, with no significant change observed in other models with strong RhoA activation (BTBR $+z$ scores 1.80 and 4.13, Cntnap2 $\mathrm{KO} z$-scores 1.40 and 1.98) or inhibition (Cacna1c* $z$-score -2.60 , Anks 1b Het $z$-scores -2.34 and -2.69) (Figure 8C). For Cdc42, expression was markedly reduced across all mouse models except the Shank3* and Anks1b Het mice (Figure 8D). Accordingly, the Cdc42 signaling pathway was predicted to be activated in the Fmr1 KO (z-scores 2.36 and 3.00), Pten Het (zscores 3.77 and 1.50), BTBR+ (z-scores 2.36 and 1.5), and Cntnap2 KO (z-scores 2.36 and 1.00). 
However, the Cacna1 $\mathrm{c}^{*}$ model showed predicted inhibition of Cdc42 signaling (z-score -2.36), as of the other Rho GTPases. Although they showed no change in total Cdc42 expression, predicted changes for Cdc42 activation were weaker in Shank3* (z-score 0.94) and Anks $1 b$ Het models ( $z$-scores -0.50 and 1.50) compared to other Rho GTPases in these mice (Table 1). Overall, the correlation between reduced total Cdc42 expression (by Western blot) with strong synaptic Cdc42 activation (in IPA) reflects the pattern in Racl and RhoA across mouse models. While several ASD models associated with synaptic Rho GTPase activation show global downregulation of GTPase expression (Fmr1 KO, Pten Het, BTBR+, Cntnap2 KO, Shank3*), others with predicted Rho inhibition demonstrate global upregulation (Cacnalc* and Ankslb Het).

\section{Discussion}

Here we compared the hippocampal postsynaptic proteomes from 7 mouse models for autism using quantitative mass spectrometry with isobaric tags (Figure 1), generating a resource for each model that can be mined for functional insights (Supplementary Data 1). Regulatory networks predicted by synaptic changes in each model reveal both novel results and patterns consistent with the literature (Figure 4, Figure 5, Error! Reference source not found.). In the Fmr1 KO model, regulatory effects showed that most proteins were upregulated (Figure 4A-B), which is consistent with a proteomic analysis of cortical synapses across the lifespan in Fmrl knockout mice (Tang et al. 2015). In the model of constitutive Pten haploinsufficiency, synaptic dysfunction (Figure 4C-D) is likely due to neuronal Pten, since altered synaptic composition was also observed in a neuron-specific conditional knockout mouse that displayed changes in activity patterns and repetitive behavior (Lugo et al. 2014). In the Cntnap2 KO mouse, the observed changes predicting increased seizures (Figure 5B, Error! Reference source not found.E) are consistent with clinical features of cortical dysplasia-focal epilepsy syndrome (Smogavec et al. 2016). Differences in the Shank3* model were milder than those observed in a previous study of the synaptic proteome in a Shank3 knockout mouse (Reim, et al. 2017), although many different Shank3 models have been developed that show distinct phenotypes (Varghese, et al. 2017). The Shank3 InsG3680 mutation examined in this study models a human SHANK3 mutation from a patient with autism, as opposed to other variants associated with schizophrenia and intellectual disability phenotypes in Phelan McDermid syndrome (Zhou, et al. 2016). For the Cacna1c* model, networks affecting heart failure and ion transport (Error! Reference source not found.G) were expected since Timothy syndrome is defined by calcium channel dysfunction leading to cardiac defects (Bader, et al. 2011). Regulatory effects in the Anks $1 \mathrm{~b}$ Het model showed subtle changes, with some similarities to Fmr1 KO and Pten Het models (Kdm5a inhibition, Error! Reference source not found.I) and some differences (Erg inhibition, Figure 5G). Predicted downregulation of synaptic genes by inhibited Erg and Ptfla (Figure 5G, Error! Reference source not found.H) is relevant to Anks $1 b$ function, since its encoded protein AIDA-1 is a synapse-to-nucleus messenger that activates protein synthesis in response to synaptic activity (Jordan, et al. 2007). For the BTBR+ model, inhibited Fev and Neurod 1 were shared with the Cacnalc* model, although BTBR+ mice shared the most upstream gene regulators with the Fmr1 KO and Pten Het models overall (Figure 2C-D).

Importantly, we directly compared synaptic proteomes in parallel, a necessary approach for finding shared phenotypes and broadly applicable therapeutic targets (Sestan and State 2018; Silverman and Ellegood 2018). Drawn from internally controlled measurements, our results demonstrate quantifiable differences in synaptic composition that support the presence of molecular subtypes in ASD rather than universal changes in the same direction. Using similarity $z$-scores and hierarchical clustering in IPA, we show that the Fmr1 KO, Pten Het models share predicted effects on upstream regulators (Figure 2C-D), diseases and functions (Figure 3), and cellular pathways (Figure 6). These results are consistent with the clinical features of the respective syndromes. In humans, macrocephaly has been observed in both Fragile X and PTEN hamartoma tumor syndromes (Butler et al. 2005; Chiu et al. 
2007). Previous studies have shown that Fmrl and Pten mouse models share behavioral traits (Binder and Lugo 2017), transcriptional profiles (Lanz et al. 2013), and altered PI3K/AKT/mTOR signaling that affects proteostasis (Gross et al. 2019; Huber et al. 2015; Richter, Bassell, and Klann 2015). Here we report divergent activation signatures between the Fmr1 KO and Shank3* mutant, which was more similar to the Cacna1c* and Cntnap2 KO models overall (Figure 2). Recent comparison of synaptic interactomes and neuroanatomical changes among ASD mouse models showed that Shank3 and Fmr loss had similar effects, although these were found in other brain regions and Shank3 deletion models (Brown, et al. 2018; Ellegood et al. 2015). Similarity between Shank3* and Cacna1c* mice is consistent with a direct behavioral comparison showing that Shank3 and Cacnalc models share hypoactivity and anxiety phenotypes (Kabitzke, et al. 2018). Abnormal social and grooming behaviors are also shared between Shank3 deletion and Cntnap2 knockout models (Kabitzke et al. 2020), along with deficits in cerebellar motor learning (Kloth et al. 2015) and adult hippocampal neurogenesis (Cope et al. 2016).

Intermediate between the Fmr1/Pten mice and the Shank3/Cntnap2/Cacnalc models, the $\mathrm{BTBR}+$ strain shows consistent similarities to Fmr1 KO and Pten Het in upstream regulators in both experiments (Figure 2C-D). As commonly studied models of syndromic and idiopathic ASD, Fmr1 KO and BTBR+ mice both respond to mGluR5 antagonism (Silverman et al. 2010), endocannabinoid potentiation (Wei et al. 2016), and intranasal dopamine (Chao et al. 2020), suggesting that changes in synaptic gene regulation can predict response to ASD treatment. Interestingly, BTBR+ and Shank3* models were only similar at the downstream level (Figure 3A), consistent with shared social phenotypes in BTBR+ and Shank3 deletion mice (Rein, Yan, and Wang 2020). Divergent gene regulation and cellular pathways at hippocampal synapses suggests that behavioral similarities in BTBR+ and Shank3 models are due to shared changes in the hippocampal cytosolic fraction (Daimon et al. 2015) or cortical interneurons (Gogolla et al. 2014). We show here that our Anks $1 b$ haploinsufficiency model is dissimilar to Fmr1 KO and Pten Het mice and similar to the Cntnap2 KO model across domains (Figure 2B,D, Figure 3B, Figure 6B). This pattern is similar to the Shank $3^{*}$ and Cacna1 ${ }^{*}$ models, although they were not directly compared to Anks $1 \mathrm{~b}$ Het mice. Interestingly, these genes all regulate synaptic formation and ion channel function, supporting a role for AIDA-1 in activity-dependent membrane composition (Carbonell, et al. 2019; Tindi, et al. 2015) and structural changes at the synapse (Li et al. 2016). Overall, our results refine and extend previous reports of the phenotypic similarities among mouse models for autism and predict that common regulators contribute to synaptic dysfunction and ASD-related phenotypes.

In the 7 autism mouse models chosen for study, changes in the synaptic proteome converged on Rho family small GTPase signaling as a commonly altered cellular pathway (Figure 6). These results complement a growing body of evidence showing that altered activation of Rho GTPases is an important mechanism of disease in autism and other neurodevelopmental disorders (Pinto et al. 2010; ZeidanChulia et al. 2013; Guo, Yang, and Shi 2020). The Rho GTPases Rac1, RhoA, and Cdc42 act as molecular switches to coordinate cellular activities at neuronal membranes, including actin-based cytoskeletal remodeling (Niftullayev and Lamarche-Vane 2019). Their activation state is positively regulated by Rho guanine nucleotide exchange factors (RhoGEFs) and negatively by Rho GTPase activating proteins (RhoGAPs). Additionally, Rho GDP dissociation inhibitors (RhoGDIs) prevent Rho GTPase activation by sequestering them in the cytosol (Reichova et al. 2018). Consistent with our findings that synaptic proteins in the Rac pathway (Figure 7) and Rac1 itself is differentially regulated in ASD mouse models (Figure 8), evidence continues to emerge that Rac1 signaling plays an important role in the pathobiology of ASD and other neurodevelopmental disorders. Rac1 mutations associated with intellectual disability impair synaptic plasticity (Tian et al. 2018). Variants in the RhoGEF TRIO can cause ASD, intellectual disability, schizophrenia, or macrocephaly, with severe phenotypes predicted by Rac1 overactivation (Barbosa et al. 2020; Sadybekov et al. 2017; Katrancha et al. 2017). Mutations in the Rac1 RhoGEF DOCK4 disrupts dendritic spine dynamics and synaptic transmission, leading to ASD, schizophrenia, and dyslexia (Huang et al. 2019; Xiao et al. 2013; Guo et al. 2019). Rac1 
overactivation through loss of RhoGAPs can cause impaired dendritic development and cognition (ARHGAP15) (Zamboni et al. 2018a); X-linked intellectual disability (OPHN1) (Busti et al. 2020); and deficits in both axonal and dendritic development (SRGAPs) (Fossati et al. 2016; Perez, Sawmiller, and Tan 2016). Downstream of Rac1 in actin polymerization, mutations in PAKs and WASF1 can cause macrocephaly, seizures, intellectual disability, or ASD (Horn et al. 2019; Ito et al. 2018).

Aside from genetic defects in its regulators and effectors, Rho GTPase pathways shows promise as a point of mechanistic convergence for other models of autism. Downstream of Fmrl, Rac1 overactivation modulates Cyfip1 regulation of dendritic spines and presynaptic morphology (De Rubeis et al. 2013; Hsiao et al. 2016). Neuroligins and neurexins, ASD-associated cell adhesion molecules related to Cntnap2, also converge on Cyfip1 function (Baudouin et al. 2012; Sledziowska, Galloway, and Baudouin 2019). Shank3 interacts with the RhoGAP Rich2 at the synapse to regulate AMPA receptor recycling and synaptic formation; loss of Rich2 leads to motor dysfunction, stereotypic behavior, and neophobia associated with Rac1 disinhibition (Raynaud et al. 2013; Sarowar et al. 2017; Sarowar et al. 2016). Shank3 also regulates NMDA receptor activity through cytoskeletal processes dependent on Rac1 (Duffney et al. 2013; Duffney et al. 2015). The ASD-related syndrome caused by 16 p11.2 copy number variations seems to converge on RhoA, which can be upregulated by loss of Kctd13 (Escamilla et al. 2017; Lin et al. 2015) or downregulated by loss of Taok2 (Richter et al. 2019). In Timothy syndrome, Cacnalc mutations cause dendritic defects related to overactivation of RhoA (Krey et al. 2013). ASD-related variants in the Stxbp5 gene lead to reduced dendritic branching and spine formation, along with reduced synaptic transmission attributed to upregulation of RhoA signaling (Shen et al. 2020; Cukier et al. 2014). Overall, Rac and RhoA pathways are commonly dysregulated in ASD and other neurodevelopmental disorders, and are therefore attractive targets for pharmacotherapy (Guo, Yang, and Shi 2020; Zamboni, et al. 2018b).

There are a number of caveats to our work. Multiple ASD models and control samples limited the number of simultaneous comparisons in 10-plex TMT-MS. Other models were excluded, including prominent genetic causes of ASD (MECP2, UBE3A, TSC1/2, SYNGAP1, NLGN/NRXN) (Hulbert and Jiang 2016; Verma, et al. 2019) and environmental risk factors (valproic acid, maternal immune activation) (Kazdoba, Leach, and Crawley 2016; Varghese, et al. 2017). However, these models affect similar pathways: Fmr1 and Ube3a regulate proteostasis, Pten and Tsc1/Tsc2 modulate $\mathrm{PI} 3 \mathrm{~K} / \mathrm{AKT} / \mathrm{mTOR}$ signaling, and Cntnap2 is a member of the Nrxn family (Bagni and Zukin 2019). Anks $1 b$ encodes the synaptic adaptor protein AIDA-1, which binds Shank3 and Syngap1 and behaves similarly as an effector of long-term potentiation (Carbonell, et al. 2019; Dosemeci et al. 2016; Li, et al. 2016; Tindi, et al. 2015). Proteomic studies of maternal immune activation also converge on synaptic dysfunction (Lombardo et al. 2018; Gyorffy et al. 2016). Comparing models at a single developmental timepoint and brain region limits the scope of observed changes, since models of ASD show behavioral and biological phenotypes that differ based on the spatiotemporal targeting of the gene (Del Pino, Rico, and Marin 2018). A proteomic study of cortical synapses noted smaller differences in Fmr1 KO mice after 3 weeks of age (Tang, et al. 2015), and both Shank3 and Syngap1 show changes in interaction partners throughout development (Li et al. 2017; Li, et al. 2016). However, young adulthood in mice is a developmental stage that can be effectively targeted through genetic and pharmacological interventions (Yan et al. 2018; Duffney, et al. 2015). Since ASD is diagnosed in early childhood, after critical periods of fetal brain development, identifying and potentially correcting molecular phenotypes that have already developed has translational value. Although hippocampal circuits have been extensively studied for their robust expression of synaptic plasticity and its implications for cognitive function, projection neurons in the neocortex, striatum, and cerebellum are also relevant to ASD animal models (Golden, Buxbaum, and De Rubeis 2018). Fractionation of the PSD limits our findings to synaptic profiles in glutamatergic neurons, but ASD risk genes also influence interneuron development (Cntnap2) (Penagarikano, et al. 2011) and oligodendrocyte maturation (Pten) (Lee et al. 2019). Importantly, the Rho GTPases that regulate synaptic changes in ASD models (Figure 6) are expressed in brain regions 
and cell types relevant to ASD: increased expression of Rac1 was found in cortical tissue from autism patients (Fatemi et al. 2013), Rac overactivation affects development of inhibitory hippocampal interneurons (Zamboni et al. 2016), and Rac1 is involved in development of oligodendrocytes and cerebellum, potentially contributing to impaired connectivity (Zeidan-Chulia et al. 2016). Future experiments to compare proteomes across cell types and developmental stages could confirm common synaptic mechanisms in brain regions, quantify relationships among monogenic ASDs, and refine molecular subtypes of autism (Sestan and State 2018; Stessman, Turner, and Eichler 2016; Iakoucheva,

Since many important risk factors for ASD converge at the synapse, investigating shared changes at the proteomic level can yield mechanistic insights and therapeutic targets. We propose that synaptic proteomes, as quantifiable phenotypes of diverse ASD models, capture the combined influences of genetic, epigenetic, transcriptomic, translational, and degradative factors implicated in ASD etiology. By focusing on the proteome, we bypass the need to understand the complex or unclear functional outcomes of these multiple factors, allowing us to directly measure their net results at the synapse. Using TMTs and quantitative proteomic methods, we found functional similarities in the postsynaptic profiles of mouse models for monogenic and idiopathic ASD. We identified Rho GTPases, especially Rac1 signaling, as crucial cellular pathways disrupted in the hippocampus across ASD mouse models. These results demonstrate that parallel processing of samples from models targeting multiple ASD risk genes can yield convergent results. They also provide a resource to supplement ongoing work in widely studied ASD mouse models and generate hypotheses for further investigation. We expect that validating Rho GTPase signaling as a point of convergence in mouse models of autism will help clarify the pathogenesis of ASD, and that future studies will pursue key nodes in the Rac1 signaling cascade as potential therapeutic targets. 
bioRxiv preprint doi: https:/doi.org/10.1101/2021.02.02.429412; this version posted February 2, 2021. The copyright holder for this preprint (which was not certified by peer review) is the author/funder, who has granted bioRxiv a license to display the preprint in perpetuity. It is made available under aCC-BY-NC-ND 4.0 International license.

\section{Tables and Figures}

698 Table 1. Pathways related to Rho GTPase signaling are differentially activated in the synapse 699 across mouse models of autism.

700 Results from six Canonical Pathways in IPA related to Rho GTPase signaling are shown for ASD mouse 701 models in Experiments 1 and 2. Overlap - $\log _{10}(p$-values) are based on the enrichment of pathway 702 703 704 705 components observed in each proteome from Fisher's exact test, and ratio is the fraction of pathway components observed: these values are constant within each experiment. Activation $z$-scores are predicted based on observed protein fold changes in each model and differ based on altered proteome composition in each model and experiment.

\begin{tabular}{|c|c|c|c|c|c|c|}
\hline \multirow{2}{*}{ Canonical Pathway } & \multicolumn{3}{|c|}{ EXPERIMENT 1} & \multicolumn{3}{|c|}{ EXPERIMENT 2} \\
\hline & $-\log _{10} p$ (ratio) & Model & $z$-score & $-\log _{10} p$ (ratio) & Model & $z$-score \\
\hline \multirow{6}{*}{$\begin{array}{c}\text { Signaling by Rho Family } \\
\text { GTPases }\end{array}$} & \multirow{6}{*}{$17.6(0.172)$} & Fmr1 KO & 4.70 & \multirow{6}{*}{$18.9(0.184)$} & Fmr1 KO & 0.82 \\
\hline & & Pten Het & 3.31 & & Pten Het & 5.43 \\
\hline & & BTBR+ & 0.17 & & BTBR+ & 2.80 \\
\hline & & Cntnap2 KO & -0.17 & & Cntnap2 KO & 0.82 \\
\hline & & Shank3* & 0.52 & & Anks $1 \mathrm{~b}$ Het 1 & -2.47 \\
\hline & & Cacna1c* & -4.35 & & Anks $1 \mathrm{~b}$ Het 2 & -4.77 \\
\hline \multirow{6}{*}{ Rac Signaling } & \multirow{6}{*}{$12.5(0.214)$} & Fmr1 KO & 3.96 & \multirow{6}{*}{$8.5(0.179)$} & Fmr1 KO & 2.98 \\
\hline & & Pten Het & 3.13 & & Pten Het & 3.44 \\
\hline & & BTBR+ & 1.04 & & BTBR+ & 2.52 \\
\hline & & Cntnap2 KO & 0.21 & & Cntnap2 KO & 0.69 \\
\hline & & Shank3* & 0.63 & & Anks $1 \mathrm{~b}$ Het 1 & -0.69 \\
\hline & & Cacna1c* & -3.96 & & Anks $1 \mathrm{~b}$ Het 2 & -2.98 \\
\hline \multirow{6}{*}{ RhoA Signaling } & \multirow{6}{*}{$13.3(0.211)$} & Fmr1 KO & 3.00 & \multirow{6}{*}{$19.3(0.268)$} & Fmr1 KO & 1.26 \\
\hline & & Pten Het & 3.40 & & Pten Het & 3.41 \\
\hline & & BTBR+ & 1.80 & & BTBR+ & 4.13 \\
\hline & & Cntnap2 KO & 1.40 & & Cntnap2 KO & 1.98 \\
\hline & & Shank3* & 1.80 & & Anks $1 \mathrm{~b}$ Het 1 & -2.34 \\
\hline & & Cacna1c ${ }^{*}$ & -2.60 & & Anks $1 \mathrm{~b}$ Het 2 & -2.69 \\
\hline \multirow{6}{*}{ Cdc42 Signaling } & \multirow{6}{*}{$4.85(0.108)$} & Fmr1 KO & 2.36 & \multirow{6}{*}{$5.57(0.120)$} & Fmr1 KO & 3.00 \\
\hline & & Pten Het & 3.77 & & Pten Het & 1.50 \\
\hline & & BTBR+ & 2.36 & & BTBR+ & 1.50 \\
\hline & & Cntnap2 KO & 2.36 & & Cntnap2 KO & 1.00 \\
\hline & & Shank3* & 0.94 & & Anks $1 \mathrm{~b}$ Het 1 & -0.50 \\
\hline & & Cacna1c* & -2.36 & & Anks $1 \mathrm{~b}$ Het 2 & -1.50 \\
\hline \multirow{6}{*}{ RhoGDI Signaling } & \multirow{6}{*}{$17.4(0.200)$} & Fmr1 KO & -4.91 & \multirow{6}{*}{$13.9(0.183)$} & Fmr1 KO & -1.80 \\
\hline & & Pten Het & -3.40 & & Pten Het & -3.80 \\
\hline & & BTBR+ & -0.38 & & BTBR+ & -2.20 \\
\hline & & Cntnap2 KO & -0.38 & & Cntnap2 KO & -1.00 \\
\hline & & Shank3* & -0.38 & & Anks $1 \mathrm{~b}$ Het 1 & 1.00 \\
\hline & & Cacna1c* & 3.78 & & Anks $1 \mathrm{~b}$ Het 2 & 3.40 \\
\hline \multirow{6}{*}{$\begin{array}{l}\text { Regulation of Actin-based } \\
\text { Motility by Rho }\end{array}$} & \multirow{6}{*}{$11.4(0.223)$} & $\mathrm{Fmr1} \mathrm{KO}$ & 2.98 & \multirow{6}{*}{$6.63(0.170)$} & $\mathrm{Fmr1} \mathrm{KO}$ & 2.32 \\
\hline & & Pten Het & 3.44 & & Pten Het & 1.81 \\
\hline & & BTBR+ & 2.52 & & BTBR+ & 2.84 \\
\hline & & Cntnap2 KO & 1.61 & & Cntnap2 KO & 2.32 \\
\hline & & Shank3* & 1.15 & & Anks $1 \mathrm{~b}$ Het 1 & -1.29 \\
\hline & & Cacna1c* & -2.07 & & Anks1b Het 2 & -1.81 \\
\hline
\end{tabular}




\section{Figure 1. Fractionation of mouse hippocampus yields the postsynaptic proteome.}

708 A) Total lysate and postsynaptic density (PSD) enriched fractions from mouse models of autism spectrum disorder (ASD) demonstrate qualitative enrichment for the synaptic marker PSD95 by Western blot (4 $\mu \mathrm{g}$ each sample). B) Comparative proteomics scheme showing parallel processing of hippocampal synaptic fractions from ASD mouse models and their control samples. Shank3* and Cacna $1 \mathrm{c}^{*}$ models were only assayed in Experiment 1, and both Anks $1 \mathrm{~b}$ Het samples were assayed in Experiment 2. C) Gene ontology (GO) analysis of the postsynaptic proteome in STRING (Experiment

715 fractions.
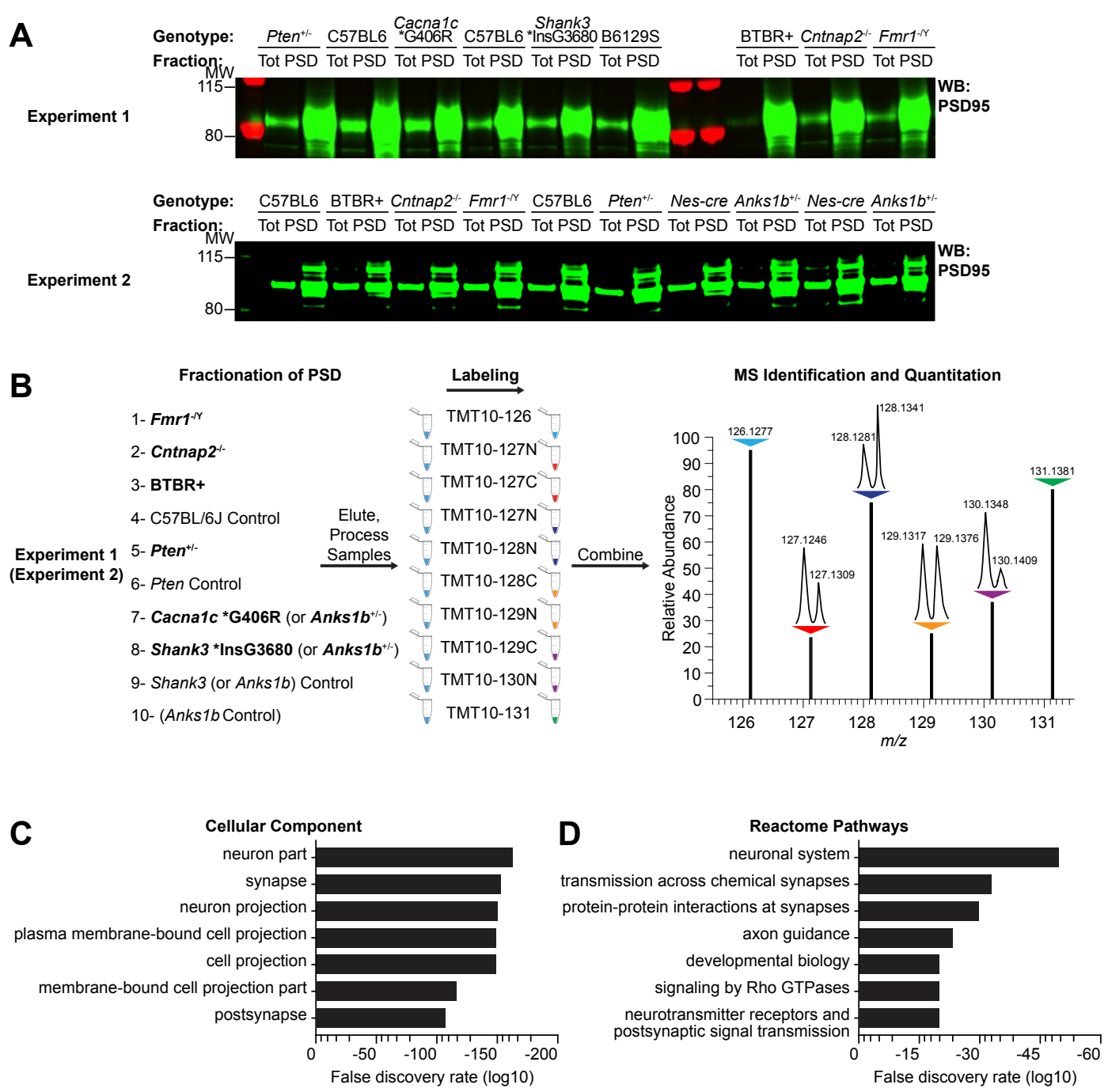
bioRxiv preprint doi: https://doi.org/10.1101/2021.02.02.429412; this version posted February 2, 2021. The copyright holder for this preprint (which was not certified by peer review) is the author/funder, who has granted bioRxiv a license to display the preprint in perpetuity. It is made available under aCC-BY-NC-ND 4.0 International license.

\section{Figure 2. Overall similarities and differences among mouse models of ASD reflect patterns in 718 predicted Upstream Regulators.}

719 A) Analysis Match in IPA scores the similarities in activation patterns among Upstream Regulators, Downstream Effects, and Canonical Pathways between ASD mouse models in Experiments 1 and 2. (B)
Overall similarity scores in Experiment 1 and Experiment 2 show congruent relationships among the Fmr1 KO, Pten Het, BTBR+, and Cntnap2 KO models examined in both experiments, and for both samples of the Anks1b Het model in Experiment 2. Cacnalc* and Shank3* mutant models were only assessed in Experiment 1. C) For Upstream Regulators alone, the same pattern of similarity among Fmr1, Pten Het, and BTBR+; as opposed to Cntnap2 KO, Shank3*, Cacna1c*, and Anks1b Het, is observed. Clustering of ASD mouse models shows the relationships among models in Experiment 1 and (D) Experiment 2. Tree diagrams show hierarchical cluster analysis of Upstream Regulators in IPA with activation $z$-scores $>|2|$ and enrichment $-\log _{10}(p$-values) $>2$ (Benjamin-Hochberg corrected for multiple comparisons).

A
\begin{tabular}{|c|c|c|c|c|c|c|}
\hline \multicolumn{7}{|c|}{ Overall Similarity z -score (p -value score) } \\
\hline & Fmr1 KO & Pten Het & BTBR+ & Cntnap2 KO & Shank3 $^{*}$ & Cacna1c $^{*}$ \\
\hline Fmr1 KO & $100(100)$ & $55.0(57)$ & $-1.9(47)$ & $-29.9(52)$ & $-50.6(51)$ & $-67.2(64)$ \\
\hline Pten Het & $66.5(57)$ & $100(100)$ & $-6.5(49)$ & $-11.3(46)$ & $-34.3(33)$ & $-78.1(62)$ \\
\hline BTBR+ & $1.6(47)$ & $1.1(49)$ & $100(100)$ & $45.2(43)$ & $-11.4(31)$ & $48.2(39)$ \\
\hline Cntnap2 KO $^{-33.5(52)}$ & $-6.6(46)$ & $42.3(43)$ & $100(100)$ & $12.6(45)$ & $38.1(43)$ \\
\hline Shank3 $^{*}$ & $-60.6(51)$ & $-32.2(33)$ & $-3.2(31)$ & $17.4(45)$ & $100(100)$ & $44.6(44)$ \\
\hline Cacna1c $^{*}$ & $-66.4(64)$ & $-64.5(62)$ & $43.2(39)$ & $33.2(43)$ & $35.5(44)$ & $100(100)$ \\
\hline
\end{tabular}

B

EXPERIMENT 2

\begin{tabular}{|c|c|c|c|c|c|c|}
\hline \multicolumn{7}{|c|}{ Overall Similarity $\mathbf{z}$-score $(\boldsymbol{p}$-value score) } \\
\hline & Pten Het & Fmr1 KO & BTBR+ & Cntnap2 KO & Anks1b Het1 & Anks1b Het2 \\
\hline Pten Het & $100(100)$ & $40.1(46)$ & $37.4(46)$ & $1.9(38)$ & $-7.9(28)$ & $-57.3(49)$ \\
\hline Fmr1 KO & $42.4(46)$ & $100(100)$ & $72.4(69)$ & $62.8(58)$ & $56.9(47)$ & $15.2(54)$ \\
\hline BTBR+ & $40.8(46)$ & $75.1(69)$ & $100(100)$ & $72.6(62)$ & $58.3(52)$ & $22.9(30)$ \\
\hline Cntnap2 KO & $0.6(38)$ & $62.0(58)$ & $70.5(62)$ & $100(100)$ & $70.9(59)$ & $61.1(48)$ \\
\hline Anks1b Het1 & $-11.5(28)$ & $60.1(47)$ & $60.7(52)$ & $75.1(58)$ & $100(100)$ & $65.0(48)$ \\
\hline Anks1b Het2 & $-56.9(49)$ & $17.6(54)$ & $25.9(30)$ & $60.3(48)$ & $60.6(48)$ & $100(100)$ \\
\hline
\end{tabular}

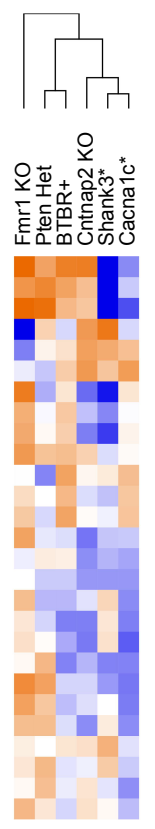

D

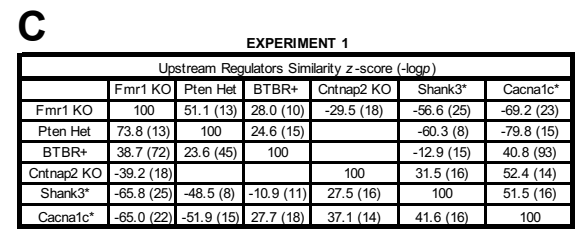

- Mlxipl [ Mycn L Myc [ Nr4a1 Rest Ppargc1b Ppargc1a Mycl - Htt Pitx2 [ Esrra - Pparg Mecp2 Zfp36I Ebf1 Hsf1 - Arnt - Nfe2l2 Fev TIx3

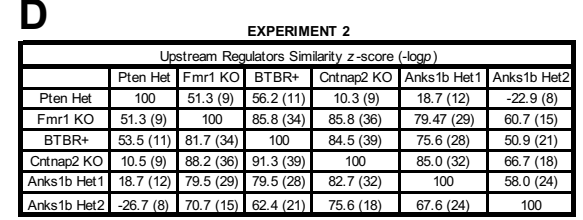

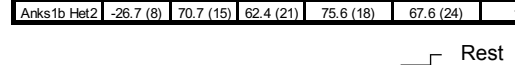

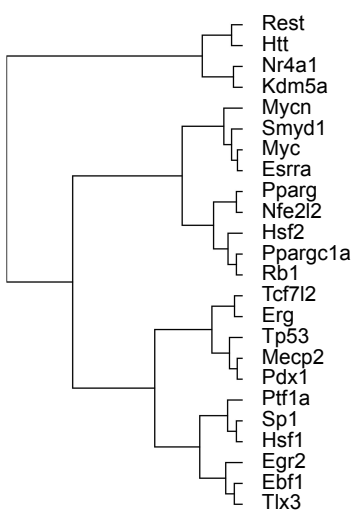

Activation z-score $-5+5$

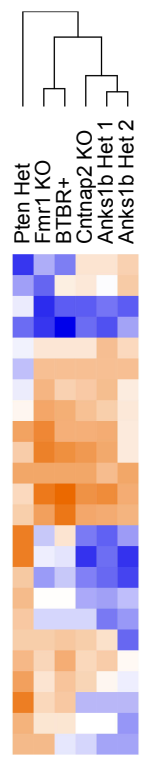
and 
bioRxiv preprint doi: https://doi.org/10.1101/2021.02.02.429412; this version posted February 2, 2021. The copyright holder for this preprint (which was not certified by peer review) is the author/funder, who has granted bioRxiv a license to display the preprint in perpetuity. It is made available under aCC-BY-NC-ND 4.0 International license.

\section{Figure 3. Predicted Downstream Effects on diseases and functions show patterns among mouse 732 models that are consistent with Overall and Upstream Regulators.}

733 A) For Downstream Effects, similarity scores among ASD mouse models in Experiment 1 and Experiment 2 show similarities among the Fmr1 KO, Pten Het, BTBR+, and Shank3* model, as opposed to the Cntnap2 KO, Cacnalc*, and Anks $1 b$ Het model (B). Clustering of ASD mouse models shows the relationships among mouse models in Experiment 1 and Experiment 2. Tree diagrams show hierarchical cluster analysis of Downstream Effects in IPA with activation $z$-scores $>|2|$ and enrichment $\log _{10}(p$-values) $>25$ (Benjamini-Hochberg corrected for multiple comparisons).

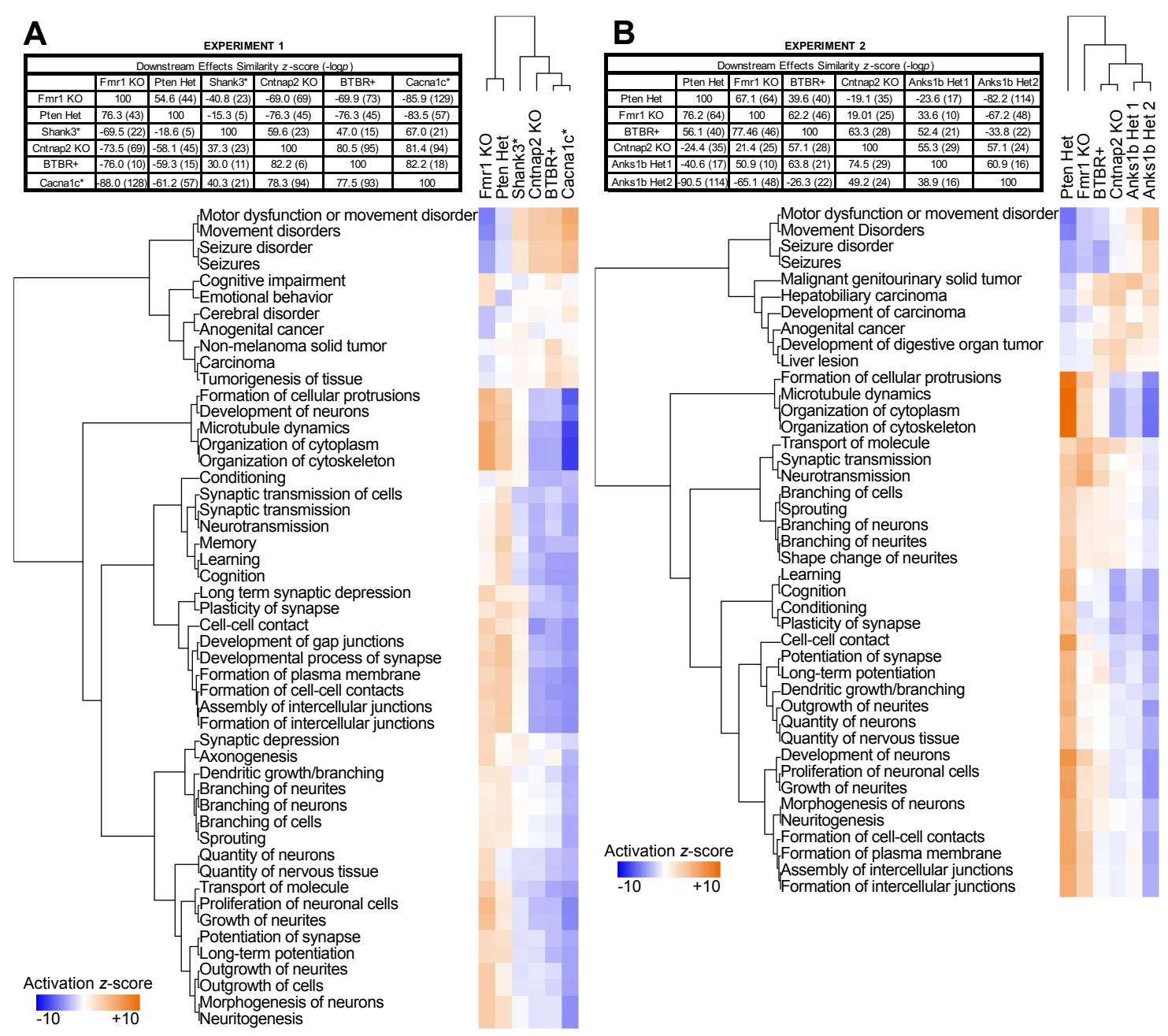


bioRxiv preprint doi: https://doi.org/10.1101/2021.02 02 429412. this version posted February 2, 2021. The copyright holder for this preprint (which was not certified by peer review) is the author/funder, who has granted bioRxiv a license to display the preprint in perpetuity. It is made available under aCC-BY-NC-ND 4.0 International license.

740 Figure 4. Altered synaptic composition predicts similar networks of functional effects in Fmr1

741 KO, Pten Het, and BTBR+ mice.

742 A-B) Top regulatory networks for Fmr1 KO mice. C-D) Top regulatory networks for Pten Het mice. E-

743 F) Top regulatory networks for BTBR+ mice. Upstream regulators and downstream effects were

744 predicted in IPA from fold-changes of proteins in the postsynaptic proteome.
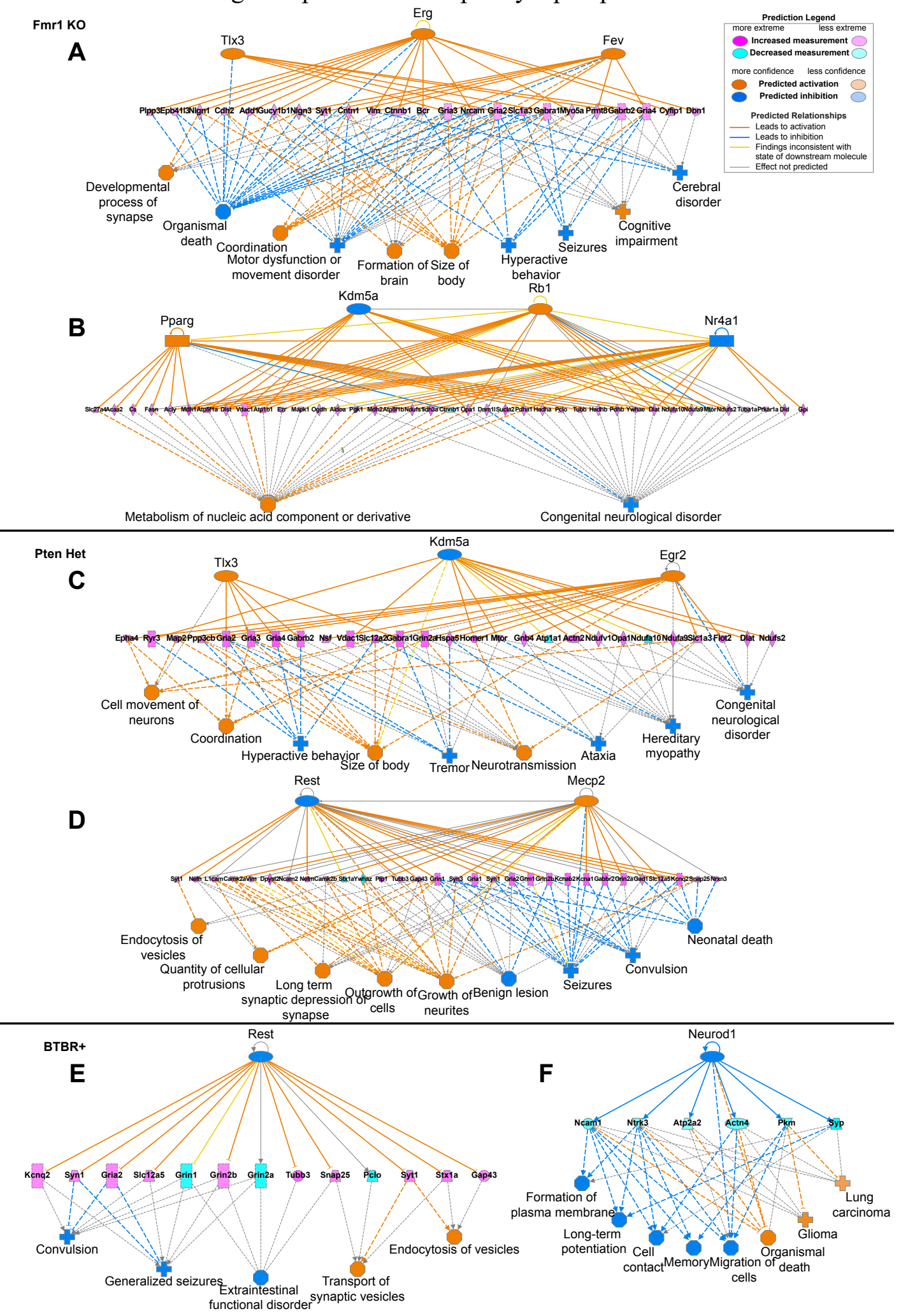
bioRxiv preprint doi: https://doi.org/10.1101/2021.02.02.429412; this version posted February 2, 2021. The copyright holder for this preprint (which was not certified by peer review) is the author/funder, who has granted bioRxiv a license to display the preprint in perpetuity. It is made available under aCC-BY-NC-ND 4.0 International license.

746 Figure 5. Altered synaptic composition predicts similar networks of functional effects in Cntnap2 747 KO, Shank3*, Cacna1c*, and Anks1b Het mice.

748 A-C) Top regulatory networks for Cntnap2 KO mice. D) Top regulatory network for Shank3* mice. E749 F) Top regulatory networks for Cacnalc* mice. G) Top regulatory networks for Anks $1 \mathrm{~b}$ Het mice.

750 Upstream regulators and downstream effects were predicted in IPA from fold-changes of proteins in the 751 postsynaptic proteome.
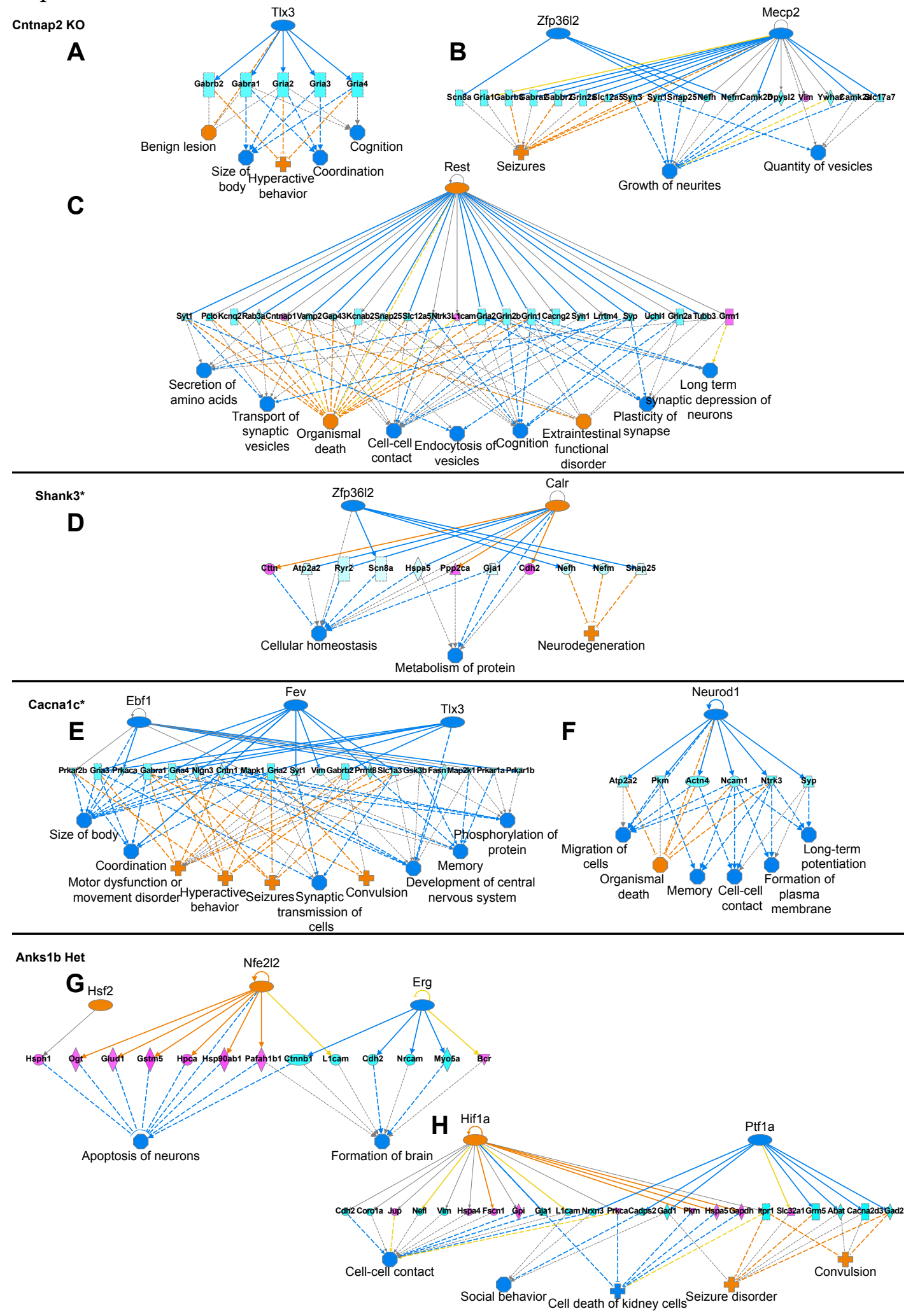
bioRxiv preprint doi: https://doi.org/10.1101/2021.02.02.429412; this version posted February 2, 2021. The copyright holder for this preprint (which was not certified by peer review) is the author/funder, who has granted bioRxiv a license to display the preprint in perpetuity. It is made available under aCC-BY-NC-ND 4.0 International license.

\section{Figure 6. Predicted effects on Canonical Pathways show a distinct pattern of similarities and 754 differences among mouse models of autism.}

755 A) For Canonical Pathways, similarity scores among ASD mouse models in Experiment 1 and Experiment 2 show similarities between the Fmr1 KO and Pten Het models, as opposed to the BTBR+, Cntnap2 KO, Shank3*, Cacna1c*, and Anks1b Het models (B). Clustering of ASD mouse models shows relationships among mouse models in Experiment 1 and Experiment 2. Tree diagrams show hierarchical cluster analysis of Canonical Pathways in IPA with activation $z$-scores $>|2|$ and enrichment $-\log _{10}(p$ values) $>5$ (Benjamin-Hochberg corrected for multiple comparisons).

A

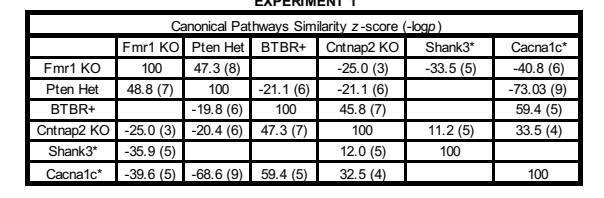

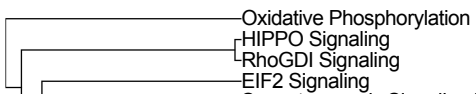
\begin{tabular}{|l} 
Oxidative Phosphor \\
HIPPO Signaling \\
HRoGDI Signaling \\
EIF2 Signaling
\end{tabular} EIF2 Signaling Synaptogenesis Signaling Remodeling Epithelial Adherens Junctions Actin Nucleation by ARP-WASP Complex Regulation of Actin-based Motility by Rho RhoA Signaling Rac Signalin

Signaling by Rho Family GTPases fMLP Signaling in Neutrophils Actin Cytoskeleton Signaling Fcy Receptor Phagocytosis Integrin Signaling Protein Kinase A Signaling 14-3-3-mediated Signaling nhibition of ARE mRNA Degradation Ephrin Receptor Signaling

Nitric Oxide in the Cardiovascular System Nitric Oxide in the Cardiovascular System DNRH Sigaling

[TNRH Signaling

Neuropathic Pain In Dorsal Horn Neurons CREB Signaling in Neurons

Synaptic Long Term Potentiation Insulin Secretion Signaling Pathway Geta Gamma Signaling

Synaptic Long Term Depression

Calcium Signaling

White Adipose Tissue Browning Pathway Netrin Signaling

Enteroendocrine GPCR Nutrient Sensing Androgen Signaling

Role of NFAT in Cardiac Hypertrophy Gluconeogenesis I Glycolysis I

Ephrin B Signaling

Estrogen Receptor Signaling

TCA Cycle II (Eukaryotic)

CDK5 Signaling

Cardiac $\beta$-adrenergic Signaling nNOS Signaling in Neuron

[PKCO Signaling in T Lymphocytes eNOS Signaling

.

p70S6K Signaling

p70S6K Signaling

CAMP-mediated signaling

Endocannabinoid Developing Neurons CXCR4 Signaling

P2Y Purigenic Receptor Pathway

Aldosterone Signaling in Epithelial Cells ERK/MAPK Signaling

HIF1a Signaling

Glutamate Receptor Signaling

Amyotrophic Lateral Sclerosis Signaling

Endocannabinoid

Melatonin Signaling

Relaxin Signaling

Amyloid Processing

Gas Signaling

IL-1 Signaling

Activation z-score

PFKFB4 Signaling Pathway

tivation $2-5 c 0$

CCR5 Signaling in Macrophages

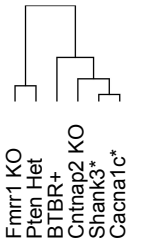

B

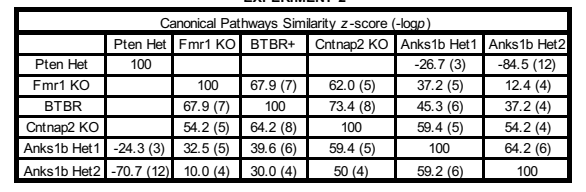

RhoGDI Signaling

HIPPO Signaling

Semaphorin Neuronal Repulsion

Oxidative Phosphorylation

Gluconeogenesis I

TCA Cycle II (Eukaryotic)

Glycolysis |

Synaptogenesis Signaling Pathway

Signaling by Rho Family GTPases

Reelin Signaling in Neurons

[Amyotrophic Lateral Sclerosis Signaling

Estrogen Receptor Signaling

Corticotropin Releasing Hormone

14-3-3-mediated Signaling

Protein Kinase A Signaling

Ketolysis

a-Adrenergic Signaling

Melatonin Signaling

Chemokine Signalin

Gaq Signaling in

fIMLP Signaling in Neutrophils

Dignaling

[LFKFB4 Sign

(1)

GNRH Signaling

in Cardiac Hypertrophy

Gas Signaling

Isoleucine Degradation I

Aldosterone Signaling in Epithelial Cells

CCR5 Signaling in Macrophages

CCR3 Signaling in Eosinophils

G Beta Gamma Signaling

Androgen Signaling

White Adipose Tissue Browning Pathway

insulin Secretion Signaling Pathway

Neuropathic Pain In Dorsal Horn Neuron

CREB Signaling in Neurons

Opioid Signaling Pathway

Calcium Signaling

Synaptic Long Term Potentiation Netrin Signaling

Synaptic Long Term Depression -RhoA Signaling

Eph 5 Rigecetor Signaling

Regulation of Actin-based Motility by Rho

Remodeling Epithelial Adherens Junctions IFcy Receptor-mediated Phagocytosis eNOS Signaling

Nitric Oxide in the Cardiovascular System Endocannabinoid Neuronal Synapse

Actin Cytoskeleton Signaling

Integrin Signaling

Amyloid Processing

cAMP-mediated signaling

Thrombin Signaling

Activation z-score

Leukocyte Extravas

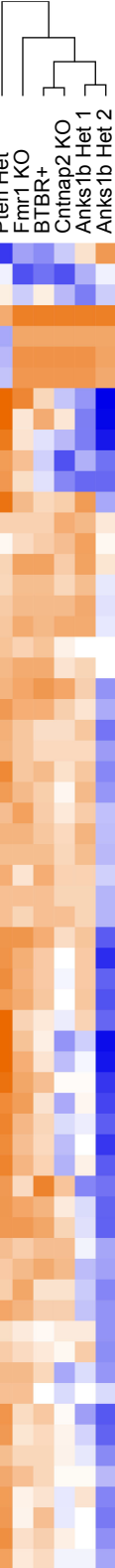


bioRxiv preprint doi: https://doi.org/10.1101/2021.02.02.429412; this version posted February 2, 2021. The copyright holder for this preprint (which was not certified by peer review) is the author/funder, who has granted bioRxiv a license to display the preprint in perpetuity. It is made available under aCC-BY-NC-ND 4.0 International license.

762

763

764

765

766

767

768

769

Figure 7. Rac Signaling Pathway is differentially regulated across mouse models of autism. Protein components of the Rac Signaling Pathway in IPA, are up- or downregulated in the postsynaptic proteomes of ASD mouse models, leading to predicted effects on pathway activation in A) Fmrl KO mice (Experiment 1), B) BTBR+ mice (Experiment 2), C) Cacnalc* KO mice (Experiment 1), and D) Anks $1 \mathrm{~b}$ Het mice $($ Experiment 2). Purple outline $=$ observed in proteome, Magenta $=$ observed increase, Cyan $=$ observed decrease, Orange arrow or fill $=$ predicted activation, Blue arrow or fill $=$ predicted inhibition, Yellow arrow $=$ predicted effect inconsistent, Gray arrow or outline $=$ effect not predicted, Solid line $=$ direct effect, Dashed line $=$ indirect effect.
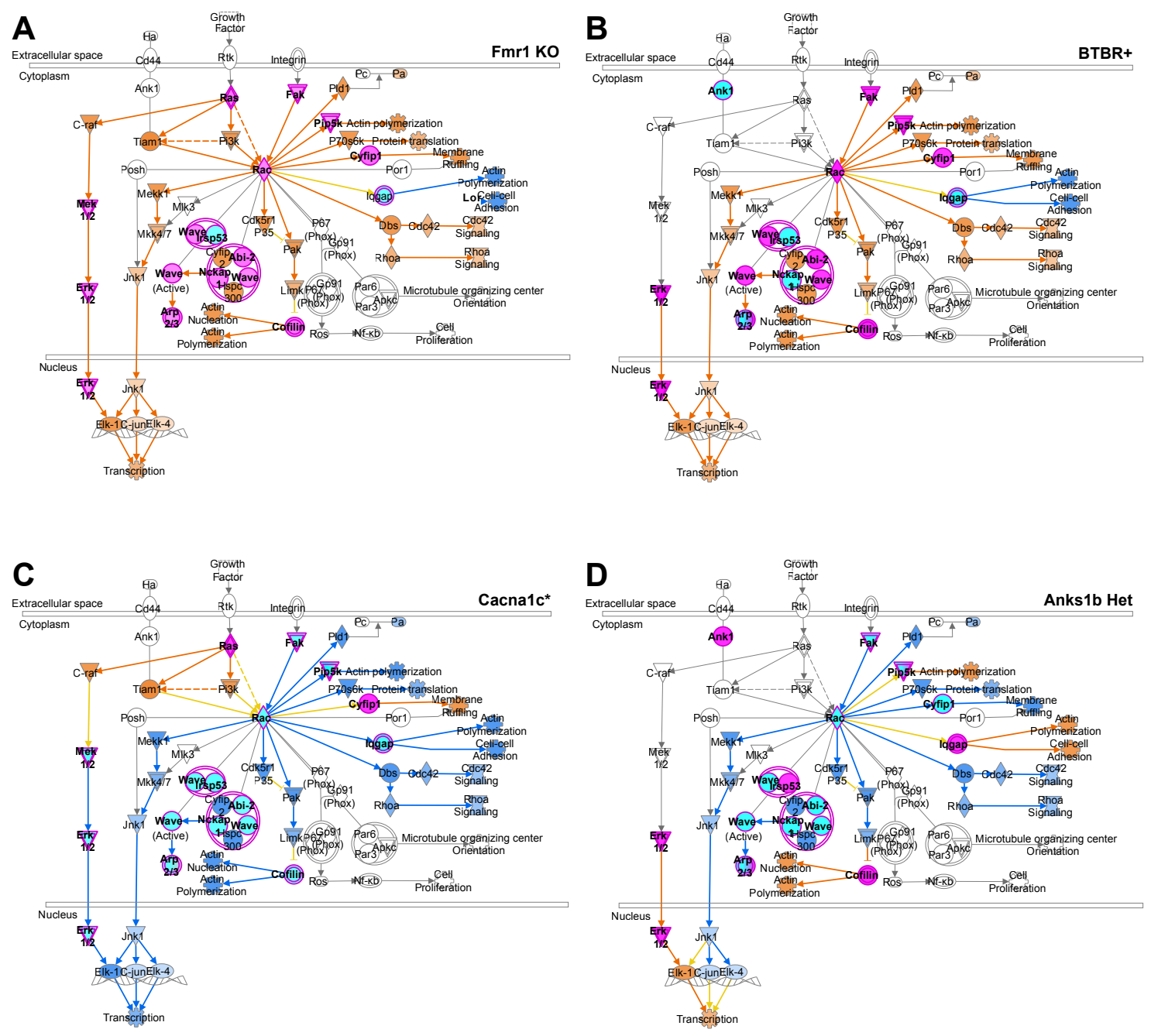
bioRxiv preprint doi: https://doi.org/10.1101/2021.02.02.429412; this version posted February 2, 2021. The copyright holder for this preprint (which was not certified by peer review) is the author/funder, who has granted bioRxiv a license to display the preprint in perpetuity. It is made available under aCC-BY-NC-ND 4.0 International license.

771 Figure 8. Rac1 is differentially expressed in synaptic fractions, and other Rho GTPases in total 772 lysate, across mouse models of autism.

773 A) Expression of Rac1, the only Rho GTPase detected in synaptic fractions, was (B) increased in Fmr1 KO, Pten Het, and Anks $1 b$ Het mice by Western blot (20 $\mu \mathrm{g}$ synaptic fraction). C) Expression of Rac1 in total lysate was reduced in all mouse models except the Cacna $1 c^{*}$ model, where it was increased. D) Expression of RhoA in total lysate was reduced for Fmr1 KO, Pten Het, and Shank3* mice only. E) Expression of Cdc42 in total lysate was reduced for all models except Shank3* and Anks1b Het models, where no significant change was observed (30 $\mu$ g total lysate). Bar graphs show mean $\pm \mathrm{SEM}, n=3-10$ samples for each mouse model and wild-type control strain, Student's $t$-test, ${ }^{*} p<0.05 * * p<0.01$ $* * * p<0.001$ as in Error! Reference source not found..

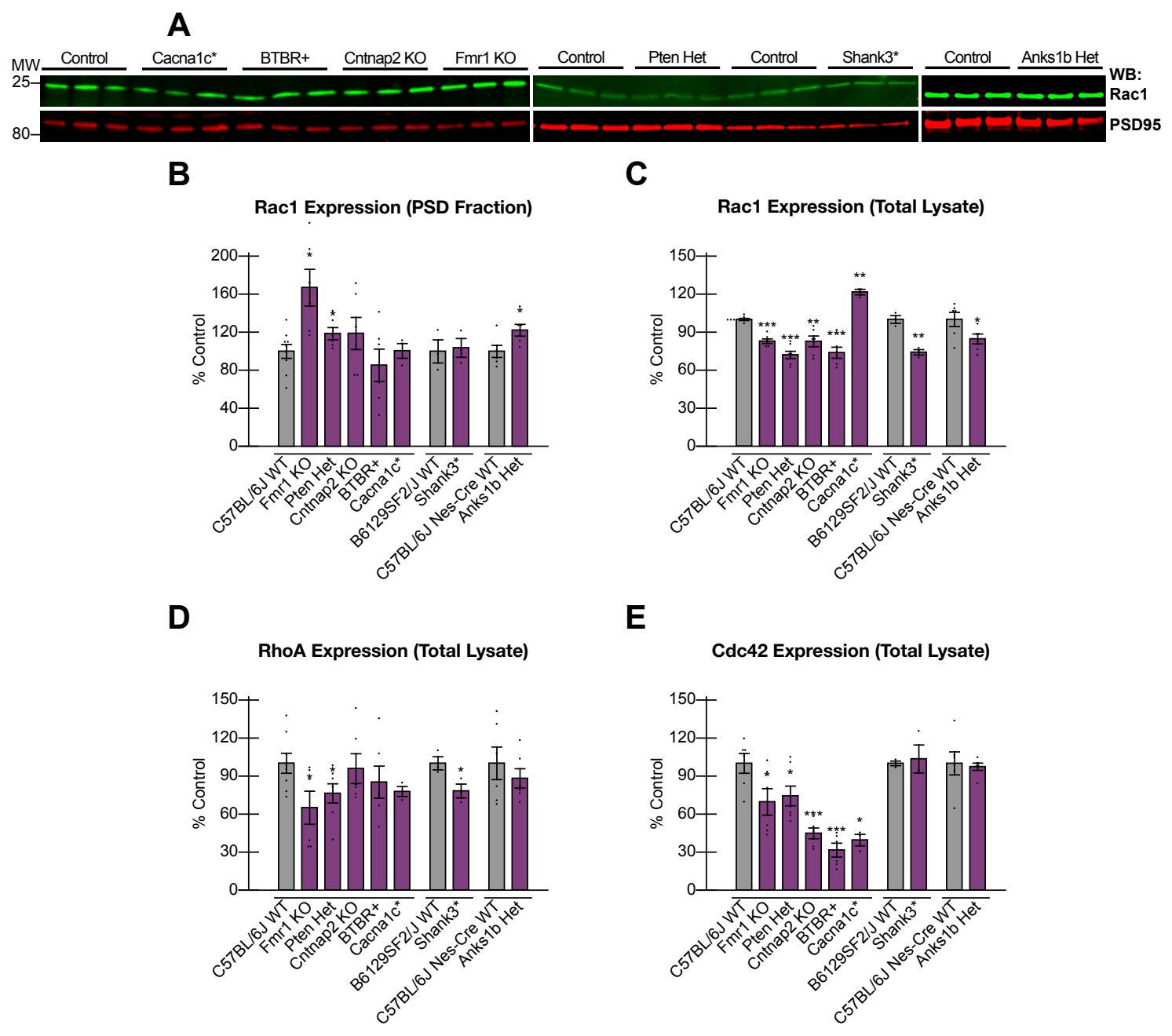


bioRxiv preprint doi: https://doi.org/10.1101/2021.02.02.429412; this version posted February 2, 2021. The copyright holder for this preprint

(which was not certified by peer review) is the author/funder, who has granted bioRxiv a license to display the preprint in perpetuity. It is made available under aCC-BY-NC-ND 4.0 International license.

\section{References}

783

784

785

786

787

788

789

790

791

792

793

794

795

796

797

798

799

800

801

802

803

804

805

806

807

808

809

810

811

812

813

814

815

816

817

818

819

820

821

822

823

824

825

826

827

828

829

Abraham, J. R., N. Szoko, J. Barnard, R. A. Rubin, D. Schlatzer, K. Lundberg, . . . M. R. Natowicz. 2019. "Proteomic Investigations of Autism Brain Identify Known and Novel Pathogenetic Processes." Sci Rep 9, no. 1 (Sep 11): 13118. https://dx.doi.org/10.1038/s41598-019-49533-y.

Andoh, M., K. Shibata, K. Okamoto, J. Onodera, K. Morishita, Y. Miura, .. R. Koyama. 2019. "Exercise Reverses Behavioral and Synaptic Abnormalities after Maternal Inflammation." Cell Rep 27, no. 10 (Jun 4): 2817-2825 e5. https://dx.doi.org/10.1016/j.celrep.2019.05.015.

Bader, P. L., M. Faizi, L. H. Kim, S. F. Owen, M. R. Tadross, R. W. Alfa, .. . M. Shamloo. 2011. "Mouse Model of Timothy Syndrome Recapitulates Triad of Autistic Traits." Proc Natl Acad Sci US A 108, no. 37 (Sep 13): 15432-7. https://dx.doi.org/10.1073/pnas.1112667108.

Bagni, C., and R. S. Zukin. 2019. "A Synaptic Perspective of Fragile X Syndrome and Autism Spectrum Disorders." Neuron 101, no. 6 (Mar 20): 1070-1088.

https://dx.doi.org/10.1016/j.neuron.2019.02.041.

Barbosa, S., S. Greville-Heygate, M. Bonnet, A. Godwin, C. Fagotto-Kaufmann, A. V. Kajava, ... D. Baralle. 2020. "Opposite Modulation of Rac1 by Mutations in Trio Is Associated with Distinct, Domain-Specific Neurodevelopmental Disorders." Am J Hum Genet 106, no. 3 (Mar 5): 338355. https://dx.doi.org/10.1016/j.ajhg.2020.01.018.

Barnes, S. A., L. S. Wijetunge, A. D. Jackson, D. Katsanevaki, E. K. Osterweil, N. H. Komiyama, ... D. J. Wyllie. 2015. "Convergence of Hippocampal Pathophysiology in Syngap+/- and Fmr1-/Y Mice." J Neurosci 35, no. 45 (Nov 11): 15073-81. https://dx.doi.org/10.1523/JNEUROSCI.1087$\underline{15.2015}$.

Baudouin, S. J., J. Gaudias, S. Gerharz, L. Hatstatt, K. Zhou, P. Punnakkal, . . P. Scheiffele. 2012. "Shared Synaptic Pathophysiology in Syndromic and Nonsyndromic Rodent Models of Autism." Science 338, no. 6103 (Oct 5): 128-32. https://dx.doi.org/10.1126/science.1224159.

Bayes, A., M. O. Collins, M. D. Croning, L. N. van de Lagemaat, J. S. Choudhary, and S. G. Grant. 2012. "Comparative Study of Human and Mouse Postsynaptic Proteomes Finds High Compositional Conservation and Abundance Differences for Key Synaptic Proteins." PLoS One 7, no. 10: e46683. https://dx.doi.org/10.1371/journal.pone.0046683.

Binder, M. S., and J. N. Lugo. 2017. "Ns-Pten Knockout Mice Show Sex- and Age-Specific Differences in Ultrasonic Vocalizations." Brain Behav 7, no. 11 (Nov): e00857. https://dx.doi.org/10.1002/brb3.857.

Bourgeron, T. 2015. "From the Genetic Architecture to Synaptic Plasticity in Autism Spectrum Disorder." Nat Rev Neurosci 16, no. 9 (Sep): 551-63. https://dx.doi.org/10.1038/nrn3992.

Brown, E. A., J. D. Lautz, T. R. Davis, E. P. Gniffke, A. A. W. VanSchoiack, S. C. Neier, . . S. E. P. Smith. 2018. "Clustering the Autisms Using Glutamate Synapse Protein Interaction Networks from Cortical and Hippocampal Tissue of Seven Mouse Models." Mol Autism 9: 48. https://dx.doi.org/10.1186/s13229-018-0229-1. 
bioRxiv preprint doi: https://doi.org/10.1101/2021.02.02.429412; this version posted February 2, 2021. The copyright holder for this preprint

(which was not certified by peer review) is the author/funder, who has granted bioRxiv a license to display the preprint in perpetuity. It is made available under aCC-BY-NC-ND 4.0 International license.

Busti, I., M. Allegra, C. Spalletti, C. Panzi, L. Restani, P. Billuart, and M. Caleo. 2020. "Rock/Pka Inhibition Rescues Hippocampal Hyperexcitability and Gabaergic Neuron Alterations in a Oligophrenin-1 Knock-out Mouse Model of X-Linked Intellectual Disability." J Neurosci 40, no. 13 (Mar 25): 2776-2788. https://dx.doi.org/10.1523/JNEUROSCI.0462-19.2020.

Butler, M. G., M. J. Dasouki, X. P. Zhou, Z. Talebizadeh, M. Brown, T. N. Takahashi, . . C. Eng. 2005. "Subset of Individuals with Autism Spectrum Disorders and Extreme Macrocephaly Associated with Germline Pten Tumour Suppressor Gene Mutations." J Med Genet 42, no. 4 (Apr): 318-21. https://dx.doi.org/10.1136/jmg.2004.024646.

Carbonell, A. U., C. H. Cho, J. O. Tindi, P. A. Counts, J. C. Bates, H. Erdjument-Bromage, . . . B. A. Jordan. 2019. "Haploinsufficiency in the Anks1b Gene Encoding Aida-1 Leads to a Neurodevelopmental Syndrome." Nat Commun 10, no. 1 (Aug 6): 3529. https://dx.doi.org/10.1038/s41467-019-11437-w.

Cellot, G., L. Maggi, M. A. Di Castro, M. Catalano, R. Migliore, M. Migliore, . . E. Cherubini. 2016. "Premature Changes in Neuronal Excitability Account for Hippocampal Network Impairment and Autistic-Like Behavior in Neonatal Btbr T+Tf/J Mice." Sci Rep 6 (Aug 16): 31696. https://dx.doi.org/10.1038/srep31696.

Chao, O. Y., S. S. Pathak, H. Zhang, N. Dunaway, J. S. Li, C. Mattern, .. Y. M. Yang. 2020. "Altered Dopaminergic Pathways and Therapeutic Effects of Intranasal Dopamine in Two Distinct Mouse Models of Autism." Mol Brain 13, no. 1 (Aug 10): 111. https://dx.doi.org/10.1186/s13041-020$\underline{00649-7 .}$.

Chiu, S., J. A. Wegelin, J. Blank, M. Jenkins, J. Day, D. Hessl, . . R. Hagerman. 2007. "Early Acceleration of Head Circumference in Children with Fragile X Syndrome and Autism." J Dev Behav Pediatr 28, no. 1 (Feb): 31-5. https://dx.doi.org/10.1097/01.DBP.0000257518.60083.2d.

Clipperton-Allen, A. E., and D. T. Page. 2014. "Pten Haploinsufficient Mice Show Broad Brain Overgrowth but Selective Impairments in Autism-Relevant Behavioral Tests." Hum Mol Genet 23, no. 13 (Jul 1): 3490-505. https://dx.doi.org/10.1093/hmg/ddu057.

---. 2015. "Decreased Aggression and Increased Repetitive Behavior in Pten Haploinsufficient Mice." Genes Brain Behav 14, no. 2 (Feb): 145-57. https://dx.doi.org/10.1111/gbb.12192.

Codina-Sola, M., M. Costa-Roger, D. Perez-Garcia, R. Flores, M. G. Palacios-Verdu, I. Cusco, and L. A. Perez-Jurado. 2019. "Genetic Factors Contributing to Autism Spectrum Disorder in WilliamsBeuren Syndrome." J Med Genet 56, no. 12 (Dec): 801-808. https://dx.doi.org/10.1136/jmedgenet-2019-106080.

Consortium, T. D.-B. F. X. 1994. "Fmr1 Knockout Mice: A Model to Study Fragile X Mental Retardation. The Dutch-Belgian Fragile X Consortium." Cell 78, no. 1 (Jul 15): 23-33. https://www.ncbi.nlm.nih.gov/pubmed/8033209.

Cope, E. C., B. A. Briones, A. T. Brockett, S. Martinez, P. A. Vigneron, M. Opendak, . . E. E. Gould. 2016. "Immature Neurons and Radial Glia, but Not Astrocytes or Microglia, Are Altered in 
bioRxiv preprint doi: https://doi.org/10.1101/2021.02.02.429412; this version posted February 2, 2021. The copyright holder for this preprint

(which was not certified by peer review) is the author/funder, who has granted bioRxiv a license to display the preprint in perpetuity. It is made available under aCC-BY-NC-ND 4.0 International license.

Adult Cntnap2 and Shank3 Mice, Models of Autism." eNeuro 3, no. 5 (Sep-Oct). https://dx.doi.org/10.1523/ENEURO.0196-16.2016.

Cox, J., N. Neuhauser, A. Michalski, R. A. Scheltema, J. V. Olsen, and M. Mann. 2011. "Andromeda: A Peptide Search Engine Integrated into the Maxquant Environment." J Proteome Res 10, no. 4 (Apr 1): 1794-805. https://dx.doi.org/10.1021/pr101065j.

Cukier, H. N., N. D. Dueker, S. H. Slifer, J. M. Lee, P. L. Whitehead, E. Lalanne, .. . M. A. PericakVance. 2014. "Exome Sequencing of Extended Families with Autism Reveals Genes Shared across Neurodevelopmental and Neuropsychiatric Disorders." Mol Autism 5, no. 1 (Jan 10): 1. https://dx.doi.org/10.1186/2040-2392-5-1.

Daimon, C. M., J. M. Jasien, W. H. Wood, 3rd, Y. Zhang, K. G. Becker, J. L. Silverman, ... S. Maudsley. 2015. "Hippocampal Transcriptomic and Proteomic Alterations in the Btbr Mouse Model of Autism Spectrum Disorder." Front Physiol 6: 324. https://dx.doi.org/10.3389/fphys.2015.00324.

De Rubeis, S., X. He, A. P. Goldberg, C. S. Poultney, K. Samocha, A. E. Cicek, .. J. J. Buxbaum. 2014. "Synaptic, Transcriptional and Chromatin Genes Disrupted in Autism." Nature 515, no. 7526 (Nov 13): 209-15. https://dx.doi.org/10.1038/nature13772.

De Rubeis, S., E. Pasciuto, K. W. Li, E. Fernandez, D. Di Marino, A. Buzzi, . . C. Bagni. 2013. "Cyfip1 Coordinates Mrna Translation and Cytoskeleton Remodeling to Ensure Proper Dendritic Spine Formation." Neuron 79, no. 6 (Sep 18): 1169-82. https://dx.doi.org/10.1016/j.neuron.2013.06.039.

Del Pino, I., B. Rico, and O. Marin. 2018. "Neural Circuit Dysfunction in Mouse Models of Neurodevelopmental Disorders." Curr Opin Neurobiol 48 (Feb): 174-182. https://dx.doi.org/10.1016/j.conb.2017.12.013.

Dosemeci, A., D. Toy, A. Burch, K. U. Bayer, and J. H. Tao-Cheng. 2016. "Camkii-Mediated Displacement of Aida-1 out of the Postsynaptic Density Core." FEBS Lett 590, no. 17 (Sep): 2934-9. https://dx.doi.org/10.1002/1873-3468.12334.

Duffney, L. J., J. Wei, J. Cheng, W. Liu, K. R. Smith, J. T. Kittler, and Z. Yan. 2013. "Shank3 Deficiency Induces Nmda Receptor Hypofunction Via an Actin-Dependent Mechanism." $J$ Neurosci 33, no. 40 (Oct 2): 15767-78. https://dx.doi.org/10.1523/JNEUROSCI.1175-13.2013.

Duffney, L. J., P. Zhong, J. Wei, E. Matas, J. Cheng, L. Qin, . . Z. Yan. 2015. "Autism-Like Deficits in Shank3-Deficient Mice Are Rescued by Targeting Actin Regulators." Cell Rep 11, no. 9 (Jun 9): 1400-1413. https://dx.doi.org/10.1016/j.celrep.2015.04.064.

Ellegood, J., E. Anagnostou, B. A. Babineau, J. N. Crawley, L. Lin, M. Genestine, . . J. P. Lerch. 2015. "Clustering Autism: Using Neuroanatomical Differences in 26 Mouse Models to Gain Insight into the Heterogeneity." Mol Psychiatry 20, no. 1 (Feb): 118-25. https://dx.doi.org/10.1038/mp.2014.98. 
bioRxiv preprint doi: https://doi.org/10.1101/2021.02.02.429412; this version posted February 2, 2021. The copyright holder for this preprint

(which was not certified by peer review) is the author/funder, who has granted bioRxiv a license to display the preprint in perpetuity. It is made available under aCC-BY-NC-ND 4.0 International license.

Erdjument-Bromage, H., F. K. Huang, and T. A. Neubert. 2018. "Sample Preparation for Relative Quantitation of Proteins Using Tandem Mass Tags (Tmt) and Mass Spectrometry (Ms)." Methods Mol Biol 1741: 135-149. https://dx.doi.org/10.1007/978-1-4939-7659-1_11.

Escamilla, C. O., I. Filonova, A. K. Walker, Z. X. Xuan, R. Holehonnur, F. Espinosa, . . C. M. Powell. 2017. "Kctd13 Deletion Reduces Synaptic Transmission Via Increased Rhoa." Nature 551, no. 7679 (Nov 9): 227-231. https://dx.doi.org/10.1038/nature24470.

Fatemi, S. H., T. D. Folsom, R. E. Kneeland, M. K. Yousefi, S. B. Liesch, and P. D. Thuras. 2013. "Impairment of Fragile X Mental Retardation Protein-Metabotropic Glutamate Receptor 5 Signaling and Its Downstream Cognates Ras-Related C3 Botulinum Toxin Substrate 1, Amyloid Beta A4 Precursor Protein, Striatal-Enriched Protein Tyrosine Phosphatase, and Homer 1, in Autism: A Postmortem Study in Cerebellar Vermis and Superior Frontal Cortex." Mol Autism 4, no. 1 (Jun 26): 21. https://dx.doi.org/10.1186/2040-2392-4-21.

Fores-Martos, J., F. Catala-Lopez, J. Sanchez-Valle, K. Ibanez, H. Tejero, H. Palma-Gudiel, . . R. Tabares-Seisdedos. 2019. "Transcriptomic Metaanalyses of Autistic Brains Reveals Shared Gene Expression and Biological Pathway Abnormalities with Cancer." Mol Autism 10: 17. https://dx.doi.org/10.1186/s13229-019-0262-8.

Fossati, M., R. Pizzarelli, E. R. Schmidt, J. V. Kupferman, D. Stroebel, F. Polleux, and C. Charrier. 2016. "Srgap2 and Its Human-Specific Paralog Co-Regulate the Development of Excitatory and Inhibitory Synapses." Neuron 91, no. 2 (Jul 20): 356-69. https://dx.doi.org/10.1016/j.neuron.2016.06.013.

Gaugler, T., L. Klei, S. J. Sanders, C. A. Bodea, A. P. Goldberg, A. B. Lee, . . J. D. Buxbaum. 2014. "Most Genetic Risk for Autism Resides with Common Variation." Nat Genet 46, no. 8 (Aug): 881-5. https://dx.doi.org/10.1038/ng.3039.

Gogolla, N., A. E. Takesian, G. Feng, M. Fagiolini, and T. K. Hensch. 2014. "Sensory Integration in Mouse Insular Cortex Reflects Gaba Circuit Maturation." Neuron 83, no. 4 (Aug 20): 894-905. https://dx.doi.org/10.1016/j.neuron.2014.06.033.

Golden, C. E., J. D. Buxbaum, and S. De Rubeis. 2018. "Disrupted Circuits in Mouse Models of Autism Spectrum Disorder and Intellectual Disability." Curr Opin Neurobiol 48 (Feb): 106-112. https://dx.doi.org/10.1016/j.conb.2017.11.006.

Gross, C., A. Banerjee, D. Tiwari, F. Longo, A. R. White, A. G. Allen, . . G. J. Bassell. 2019. "IsoformSelective Phosphoinositide 3-Kinase Inhibition Ameliorates a Broad Range of Fragile X Syndrome-Associated Deficits in a Mouse Model." Neuropsychopharmacology 44, no. 2 (Jan): 324-333. https://dx.doi.org/10.1038/s41386-018-0150-5.

Guo, D., Y. Peng, L. Wang, X. Sun, X. Wang, C. Liang, . . L. Shi. 2019. "Autism-Like Social Deficit Generated by Dock4 Deficiency Is Rescued by Restoration of Rac1 Activity and Nmda Receptor Function." Mol Psychiatry (Aug 6). https://dx.doi.org/10.1038/s41380-019-0472-7.

Guo, D., X. Yang, and L. Shi. 2020. "Rho Gtpase Regulators and Effectors in Autism Spectrum Disorders: Animal Models and Insights for Therapeutics." Cells 9, no. 4 (Mar 31). https://dx.doi.org/10.3390/cells9040835. 
bioRxiv preprint doi: https://doi.org/10.1101/2021.02.02.429412; this version posted February 2, 2021. The copyright holder for this preprint

(which was not certified by peer review) is the author/funder, who has granted bioRxiv a license to display the preprint in perpetuity. It is made available under aCC-BY-NC-ND 4.0 International license.

Gyorffy, B. A., P. Gulyassy, B. Gellen, K. Volgyi, D. Madarasi, V. Kis, ... K. A. Kekesi. 2016. "Widespread Alterations in the Synaptic Proteome of the Adolescent Cerebral Cortex Following Prenatal Immune Activation in Rats." Brain Behav Immun 56 (Aug): 289-309. https://dx.doi.org/10.1016/j.bbi.2016.04.002.

Hedrick, N. G., and R. Yasuda. 2017. "Regulation of Rho Gtpase Proteins During Spine Structural Plasticity for the Control of Local Dendritic Plasticity." Curr Opin Neurobiol 45 (Aug): 193-201. https://dx.doi.org/10.1016/j.conb.2017.06.002.

Heise, C., J. M. Preuss, J. C. Schroeder, C. R. Battaglia, J. Kolibius, R. Schmid, .. . T. M. Boeckers. 2018. "Heterogeneity of Cell Surface Glutamate and Gaba Receptor Expression in Shank and Cntn4 Autism Mouse Models." Front Mol Neurosci 11: 212. https://dx.doi.org/10.3389/fnmol.2018.00212.

Hernandez, L. M., M. Kim, G. D. Hoftman, J. R. Haney, L. de la Torre-Ubieta, B. Pasaniuc, and M. J. Gandal. 2020. "Transcriptomic Insight into the Polygenic Mechanisms Underlying Psychiatric Disorders." Biol Psychiatry (Jun 12). https://dx.doi.org/10.1016/j.biopsych.2020.06.005.

Horn, S., M. Au, L. Basel-Salmon, P. Bayrak-Toydemir, A. Chapin, L. Cohen, . . . R. Abou Jamra. 2019. "De Novo Variants in Pak1 Lead to Intellectual Disability with Macrocephaly and Seizures." Brain 142, no. 11 (Nov 1): 3351-3359. https://dx.doi.org/10.1093/brain/awz264.

Hsiao, K., H. Harony-Nicolas, J. D. Buxbaum, O. Bozdagi-Gunal, and D. L. Benson. 2016. "Cyfip1 Regulates Presynaptic Activity During Development." J Neurosci 36, no. 5 (Feb 3): 1564-76. https://dx.doi.org/10.1523/JNEUROSCI.0511-15.2016.

Huang, F. K., G. Zhang, K. Lawlor, A. Nazarian, J. Philip, P. Tempst, ... T. A. Neubert. 2017. "Deep Coverage of Global Protein Expression and Phosphorylation in Breast Tumor Cell Lines Using Tmt 10-Plex Isobaric Labeling." J Proteome Res 16, no. 3 (Mar 3): 1121-1132. https://dx.doi.org/10.1021/acs.jproteome.6b00374.

Huang, M., C. Liang, S. Li, J. Zhang, D. Guo, B. Zhao, ... L. Shi. 2019. "Two Autism/Dyslexia Linked Variations of Dock4 Disrupt the Gene Function on Rac1/Rap1 Activation, Neurite Outgrowth, and Synapse Development." Front Cell Neurosci 13: 577. https://dx.doi.org/10.3389/fncel.2019.00577.

Huang, W. C., Y. Chen, and D. T. Page. 2016. "Hyperconnectivity of Prefrontal Cortex to Amygdala Projections in a Mouse Model of Macrocephaly/Autism Syndrome." Nat Commun 7 (Nov 15): 13421. https://dx.doi.org/10.1038/ncomms13421.

Huber, K. M., E. Klann, M. Costa-Mattioli, and R. S. Zukin. 2015. "Dysregulation of Mammalian Target of Rapamycin Signaling in Mouse Models of Autism." J Neurosci 35, no. 41 (Oct 14): 13836-42. https://dx.doi.org/10.1523/JNEUROSCI.2656-15.2015.

Hulbert, S. W., and Y. H. Jiang. 2016. "Monogenic Mouse Models of Autism Spectrum Disorders: Common Mechanisms and Missing Links." Neuroscience 321 (May 3): 3-23. https://dx.doi.org/10.1016/j.neuroscience.2015.12.040. 
bioRxiv preprint doi: https://doi.org/10.1101/2021.02.02.429412; this version posted February 2, 2021. The copyright holder for this preprint

(which was not certified by peer review) is the author/funder, who has granted bioRxiv a license to display the preprint in perpetuity. It is made available under aCC-BY-NC-ND 4.0 International license.

1023

1024

1025

1026

1027

1028

1029

1030

1031

1032

1033

1034

1035

1036

1037

1038

1039

1040

1041

1042

1043

1044

1045

1046

1047

1048

1049

1050

1051

1052

1053

1054

1055

1056

1057

1058

1059

1060

1061

1062

1063

1064

1065

1066

1067

1068

1069

1070

1071

Iakoucheva, L. M., A. R. Muotri, and J. Sebat. 2019. "Getting to the Cores of Autism." Cell 178, no. 6 (Sep 5): 1287-1298. https://dx.doi.org/10.1016/j.cell.2019.07.037.

Ito, Y., K. J. Carss, S. T. Duarte, T. Hartley, B. Keren, M. A. Kurian, . . F. L. Raymond. 2018. "De Novo Truncating Mutations in Wasf1 Cause Intellectual Disability with Seizures." Am J Hum Genet 103, no. 1 (Jul 5): 144-153. https://dx.doi.org/10.1016/j.ajhg.2018.06.001.

Jordan, B. A., B. D. Fernholz, L. Khatri, and E. B. Ziff. 2007. "Activity-Dependent Aida-1 Nuclear Signaling Regulates Nucleolar Numbers and Protein Synthesis in Neurons." Nat Neurosci 10, no. 4 (Apr): 427-35. https://dx.doi.org/10.1038/nn1867.

Kabitzke, P., D. Morales, D. He, K. Cox, J. Sutphen, L. Thiede, .. . D. Brunner. 2020. "Mouse Model Systems of Autism Spectrum Disorder: Replicability and Informatics Signature." Genes Brain Behav (May 22): e12676. https://dx.doi.org/10.1111/gbb.12676.

Kabitzke, P. A., D. Brunner, D. He, P. A. Fazio, K. Cox, J. Sutphen, . . A. L. Clayton. 2018. "Comprehensive Analysis of Two Shank3 and the Cacnalc Mouse Models of Autism Spectrum Disorder." Genes Brain Behav 17, no. 1 (Jan): 4-22. https://dx.doi.org/10.1111/gbb.12405.

Kaizuka, T., and T. Takumi. 2018. "Postsynaptic Density Proteins and Their Involvement in Neurodevelopmental Disorders." J Biochem 163, no. 6 (Jun 1): 447-455. https://dx.doi.org/10.1093/jb/mvy022.

Katrancha, S. M., Y. Wu, M. Zhu, B. A. Eipper, A. J. Koleske, and R. E. Mains. 2017. "Neurodevelopmental Disease-Associated De Novo Mutations and Rare Sequence Variants Affect Trio Gdp/Gtp Exchange Factor Activity." Hum Mol Genet 26, no. 23 (Dec 1): 4728-4740. https://dx.doi.org/10.1093/hmg/ddx355.

Kazdoba, T. M., P. T. Leach, and J. N. Crawley. 2016. "Behavioral Phenotypes of Genetic Mouse Models of Autism." Genes Brain Behav 15, no. 1 (Jan): 7-26. https://dx.doi.org/10.1111/gbb.12256.

Klein, M. E., T. J. Younts, C. F. Cobo, A. R. Buxbaum, J. Aow, H. Erdjument-Bromage, ... B. A. Jordan. 2019. "Sam68 Enables Metabotropic Glutamate Receptor-Dependent Ltd in Distal Dendritic Regions of Ca1 Hippocampal Neurons." Cell Rep 29, no. 7 (Nov 12): 1789-1799 e6. https://dx.doi.org/10.1016/j.celrep.2019.10.030.

Kloth, A. D., A. Badura, A. Li, A. Cherskov, S. G. Connolly, A. Giovannucci, .. S. S. Wang. 2015. "Cerebellar Associative Sensory Learning Defects in Five Mouse Autism Models." Elife 4 (Jul 9): e06085. https://dx.doi.org/10.7554/eLife.06085.

Koopmans, F., P. van Nierop, M. Andres-Alonso, A. Byrnes, T. Cijsouw, M. P. Coba, ... M. Verhage. 2019. "Syngo: An Evidence-Based, Expert-Curated Knowledge Base for the Synapse." Neuron 103, no. 2 (Jul 17): 217-234 e4. https://dx.doi.org/10.1016/j.neuron.2019.05.002.

Kramer, A., J. Green, J. Pollard, Jr., and S. Tugendreich. 2014. "Causal Analysis Approaches in Ingenuity Pathway Analysis." Bioinformatics 30, no. 4 (Feb 15): 523-30. https://dx.doi.org/10.1093/bioinformatics/btt703. 
1072

1073

1074

1075

1076

1077

1078

1079

1080

1081

1082

1083

1084

1085

1086

1087

1088

1089

1090

1091

1092

1093

1094

1095

1096

1097

1098

1099

1100

1101

1102

1103

1104

1105

1106

1107

1108

1109

1110

1111

1112

1113

1114

1115

1116

1117

1118

1119

Krey, J. F., S. P. Pasca, A. Shcheglovitov, M. Yazawa, R. Schwemberger, R. Rasmusson, and R. E. Dolmetsch. 2013. "Timothy Syndrome Is Associated with Activity-Dependent Dendritic Retraction in Rodent and Human Neurons." Nat Neurosci 16, no. 2 (Feb): 201-9. https://dx.doi.org/10.1038/nn.3307.

Lanz, T. A., E. Guilmette, M. M. Gosink, J. E. Fischer, L. W. Fitzgerald, D. T. Stephenson, and M. T. Pletcher. 2013. "Transcriptomic Analysis of Genetically Defined Autism Candidate Genes Reveals Common Mechanisms of Action." Mol Autism 4, no. 1 (Nov 15): 45. https://dx.doi.org/10.1186/2040-2392-4-45.

Lee, H., S. Thacker, N. Sarn, R. Dutta, and C. Eng. 2019. "Constitutional Mislocalization of Pten Drives Precocious Maturation in Oligodendrocytes and Aberrant Myelination in Model of Autism Spectrum Disorder." Transl Psychiatry 9, no. 1 (Jan 17): 13. https://dx.doi.org/10.1038/s41398$\underline{018-0364-7 .}$.

Lee, Y., H. Kang, B. Lee, Y. Zhang, Y. Kim, S. Kim, .. . K. Han. 2017. "Integrative Analysis of Brain Region-Specific Shank3 Interactomes for Understanding the Heterogeneity of Neuronal Pathophysiology Related to Shank3 Mutations." Front Mol Neurosci 10: 110. https://dx.doi.org/10.3389/fnmol.2017.00110.

Li, J., M. Shi, Z. Ma, S. Zhao, G. Euskirchen, J. Ziskin, ... M. Snyder. 2014. "Integrated Systems Analysis Reveals a Molecular Network Underlying Autism Spectrum Disorders." Mol Syst Biol 10 (Dec 30): 774. https://dx.doi.org/10.15252/msb.20145487.

Li, J., B. Wilkinson, V. A. Clementel, J. Hou, T. J. O'Dell, and M. P. Coba. 2016. "Long-Term Potentiation Modulates Synaptic Phosphorylation Networks and Reshapes the Structure of the Postsynaptic Interactome." Sci Signal 9, no. 440 (Aug 9): rs8. https://dx.doi.org/10.1126/scisignal.aaf6716.

Li, J., W. Zhang, H. Yang, D. P. Howrigan, B. Wilkinson, T. Souaiaia, . . M. P. Coba. 2017. "Spatiotemporal Profile of Postsynaptic Interactomes Integrates Components of Complex Brain Disorders." Nat Neurosci 20, no. 8 (Aug): 1150-1161. https://dx.doi.org/10.1038/nn.4594.

Li, Y., G. Missig, B. C. Finger, S. M. Landino, A. J. Alexander, E. L. Mokler, . . V. Y. Bolshakov. 2018. "Maternal and Early Postnatal Immune Activation Produce Dissociable Effects on Neurotransmission in Mpfc-Amygdala Circuits." J Neurosci 38, no. 13 (Mar 28): 3358-3372. https://dx.doi.org/10.1523/JNEUROSCI.3642-17.2018.

Lin, G. N., R. Corominas, I. Lemmens, X. Yang, J. Tavernier, D. E. Hill, . . L. M. Iakoucheva. 2015. "Spatiotemporal 16p1 1.2 Protein Network Implicates Cortical Late Mid-Fetal Brain Development and Kctd13-Cul3-Rhoa Pathway in Psychiatric Diseases." Neuron 85, no. 4 (Feb 18): 742-54. https://dx.doi.org/10.1016/j.neuron.2015.01.010.

Lombardo, M. V., H. M. Moon, J. Su, T. D. Palmer, E. Courchesne, and T. Pramparo. 2018. "Maternal Immune Activation Dysregulation of the Fetal Brain Transcriptome and Relevance to the Pathophysiology of Autism Spectrum Disorder." Mol Psychiatry 23, no. 4 (Apr): 1001-1013. https://dx.doi.org/10.1038/mp.2017.15. 
bioRxiv preprint doi: https://doi.org/10.1101/2021.02.02.429412; this version posted February 2, 2021. The copyright holder for this preprint

(which was not certified by peer review) is the author/funder, who has granted bioRxiv a license to display the preprint in perpetuity. It is made available under aCC-BY-NC-ND 4.0 International license.

1120

1121

1122

1123

1124

1125

1126

1127

1128

1129

1130

1131

1132

1133

1134

1135

1136

1137

1138

1139

1140

1141

1142

1143

1144

1145

1146

1147

1148

1149

1150

1151

1152

1153

1154

1155

1156

1157

1158

1159

1160

1161

1162

1163

1164

1165

1166

1167

Louros, S. R., and E. K. Osterweil. 2016. "Perturbed Proteostasis in Autism Spectrum Disorders." J Neurochem 139, no. 6 (Dec): 1081-1092. https://dx.doi.org/10.1111/jnc.13723.

Lugo, J. N., G. D. Smith, E. P. Arbuckle, J. White, A. J. Holley, C. M. Floruta, . . O. Okonkwo. 2014. "Deletion of Pten Produces Autism-Like Behavioral Deficits and Alterations in Synaptic Proteins." Front Mol Neurosci 7: 27. https://dx.doi.org/10.3389/fnmol.2014.00027.

Martin, H. G., and O. J. Manzoni. 2014. "Late Onset Deficits in Synaptic Plasticity in the Valproic Acid Rat Model of Autism." Front Cell Neurosci 8: 23. https://dx.doi.org/10.3389/fncel.2014.00023.

McFarlane, H. G., G. K. Kusek, M. Yang, J. L. Phoenix, V. J. Bolivar, and J. N. Crawley. 2008. "Autism-Like Behavioral Phenotypes in Btbr T+Tf/J Mice." Genes Brain Behav 7, no. 2 (Mar): 152-63. https://dx.doi.org/10.1111/j.1601-183X.2007.00330.x.

Murakoshi, H., H. Wang, and R. Yasuda. 2011. "Local, Persistent Activation of Rho Gtpases During Plasticity of Single Dendritic Spines." Nature 472, no. 7341 (Apr 7): 100-4. https://dx.doi.org/10.1038/nature09823.

Murtaza, N., J. Uy, and K. K. Singh. 2020. "Emerging Proteomic Approaches to Identify the Underlying Pathophysiology of Neurodevelopmental and Neurodegenerative Disorders." Mol Autism 11, no. 1 (Apr 21): 27. https://dx.doi.org/10.1186/s13229-020-00334-5.

Niftullayev, S., and N. Lamarche-Vane. 2019. "Regulators of Rho Gtpases in the Nervous System: Molecular Implication in Axon Guidance and Neurological Disorders." Int J Mol Sci 20, no. 6 (Mar 25). https://dx.doi.org/10.3390/ijms20061497.

Pacheco, N. L., M. R. Heaven, L. M. Holt, D. K. Crossman, K. J. Boggio, S. A. Shaffer, . . M. L. Olsen. 2017. "Rna Sequencing and Proteomics Approaches Reveal Novel Deficits in the Cortex of Mecp2-Deficient Mice, a Model for Rett Syndrome." Mol Autism 8: 56. https://dx.doi.org/10.1186/s13229-017-0174-4.

Patrich, E., Y. Piontkewitz, A. Peretz, I. Weiner, and B. Attali. 2016. "Maternal Immune Activation Produces Neonatal Excitability Defects in Offspring Hippocampal Neurons from Pregnant Rats Treated with Poly I:C." Sci Rep 6 (Jan 8): 19106. https://dx.doi.org/10.1038/srep19106.

Penagarikano, O., B. S. Abrahams, E. I. Herman, K. D. Winden, A. Gdalyahu, H. Dong, .. . D. H. Geschwind. 2011. "Absence of Cntnap2 Leads to Epilepsy, Neuronal Migration Abnormalities, and Core Autism-Related Deficits." Cell 147, no. 1 (Sep 30): 235-46.

https://dx.doi.org/10.1016/j.cell.2011.08.040.

Perez, C., D. Sawmiller, and J. Tan. 2016. "The Role of Heparan Sulfate Deficiency in Autistic Phenotype: Potential Involvement of Slit/Robo/Srgaps-Mediated Dendritic Spine Formation." Neural Dev 11 (Apr 18): 11. https://dx.doi.org/10.1186/s13064-016-0066-x.

Pinto, D., E. Delaby, D. Merico, M. Barbosa, A. Merikangas, L. Klei, .. . S. W. Scherer. 2014. "Convergence of Genes and Cellular Pathways Dysregulated in Autism Spectrum Disorders." Am J Hum Genet 94, no. 5 (May 1): 677-94. https://dx.doi.org/10.1016/j.ajhg.2014.03.018. 
bioRxiv preprint doi: https://doi.org/10.1101/2021.02.02.429412; this version posted February 2, 2021. The copyright holder for this preprint

(which was not certified by peer review) is the author/funder, who has granted bioRxiv a license to display the preprint in perpetuity. It is made available under aCC-BY-NC-ND 4.0 International license.

1168

1169

1170

1171

1172

1173

1174

1175

1176

1177

1178

1179

1180

1181

1182

1183

1184

1185

1186

1187

1188

1189

1190

1191

1192

1193

1194

1195

1196

1197

1198

1199

1200

1201

1202

1203

1204

1205

1206

1207

1208

1209

1210

1211

1212

1213

1214

1215

1216

Pinto, D., A. T. Pagnamenta, L. Klei, R. Anney, D. Merico, R. Regan, . . C. Betancur. 2010.

"Functional Impact of Global Rare Copy Number Variation in Autism Spectrum Disorders." Nature 466, no. 7304 (Jul 15): 368-72. https://dx.doi.org/10.1038/nature09146.

Quesnel-Vallieres, M., R. J. Weatheritt, S. P. Cordes, and B. J. Blencowe. 2019. "Autism Spectrum Disorder: Insights into Convergent Mechanisms from Transcriptomics." Nat Rev Genet 20, no. 1 (Jan): 51-63. https://dx.doi.org/10.1038/s41576-018-0066-2.

Rappsilber, J., M. Mann, and Y. Ishihama. 2007. "Protocol for Micro-Purification, Enrichment, PreFractionation and Storage of Peptides for Proteomics Using Stagetips." Nat Protoc 2, no. 8: 1896-906. https://dx.doi.org/10.1038/nprot.2007.261.

Raynaud, F., A. Janossy, J. Dahl, F. Bertaso, J. Perroy, A. Varrault, . . V. Homburger. 2013. "Shank3Rich2 Interaction Regulates Ampa Receptor Recycling and Synaptic Long-Term Potentiation." J Neurosci 33, no. 23 (Jun 5): 9699-715. https://dx.doi.org/10.1523/JNEUROSCI.2725-12.2013.

Reichova, A., M. Zatkova, Z. Bacova, and J. Bakos. 2018. "Abnormalities in Interactions of Rho Gtpases with Scaffolding Proteins Contribute to Neurodevelopmental Disorders." J Neurosci Res 96, no. 5 (May): 781-788. https://dx.doi.org/10.1002/jnr.24200.

Reim, D., U. Distler, S. Halbedl, C. Verpelli, C. Sala, J. Bockmann, . . M. J. Schmeisser. 2017. "Proteomic Analysis of Post-Synaptic Density Fractions from Shank3 Mutant Mice Reveals Brain Region Specific Changes Relevant to Autism Spectrum Disorder." Front Mol Neurosci 10: 26. https://dx.doi.org/10.3389/fnmol.2017.00026.

Rein, B., Z. Yan, and Z. J. Wang. 2020. "Diminished Social Interaction Incentive Contributes to Social Deficits in Mouse Models of Autism Spectrum Disorder." Genes Brain Behav 19, no. 1 (Jan): e12610. https://dx.doi.org/10.1111/gbb.12610.

Richter, J. D., G. J. Bassell, and E. Klann. 2015. "Dysregulation and Restoration of Translational Homeostasis in Fragile X Syndrome." Nat Rev Neurosci 16, no. 10 (Oct): 595-605. https://dx.doi.org/10.1038/nrn4001.

Richter, M., N. Murtaza, R. Scharrenberg, S. H. White, O. Johanns, S. Walker, . . F. Calderon de Anda. 2019. "Altered Taok2 Activity Causes Autism-Related Neurodevelopmental and Cognitive Abnormalities through Rhoa Signaling." Mol Psychiatry 24, no. 9 (Sep): 1329-1350. https://dx.doi.org/10.1038/s41380-018-0025-5.

Ruzzo, E. K., L. Perez-Cano, J. Y. Jung, L. K. Wang, D. Kashef-Haghighi, C. Hartl, . . . D. P. Wall. 2019. "Inherited and De Novo Genetic Risk for Autism Impacts Shared Networks." Cell 178, no. 4 (Aug 8): 850-866 e26. https://dx.doi.org/10.1016/j.cell.2019.07.015.

Sadybekov, A., C. Tian, C. Arnesano, V. Katritch, and B. E. Herring. 2017. "An Autism Spectrum Disorder-Related De Novo Mutation Hotspot Discovered in the Gef1 Domain of Trio." Nat Commun 8, no. 1 (Sep 19): 601. https://dx.doi.org/10.1038/s41467-017-00472-0.

Sarowar, T., S. Grabrucker, T. M. Boeckers, and A. M. Grabrucker. 2017. "Object Phobia and Altered Rhoa Signaling in Amygdala of Mice Lacking Rich2." Front Mol Neurosci 10: 180. https://dx.doi.org/10.3389/fnmol.2017.00180. 
bioRxiv preprint doi: https://doi.org/10.1101/2021.02.02.429412; this version posted February 2, 2021. The copyright holder for this preprint

(which was not certified by peer review) is the author/funder, who has granted bioRxiv a license to display the preprint in perpetuity. It is made available under aCC-BY-NC-ND 4.0 International license.

Sarowar, T., S. Grabrucker, K. Fohr, K. Mangus, M. Eckert, J. Bockmann, . . A. M. Grabrucker. 2016. "Enlarged Dendritic Spines and Pronounced Neophobia in Mice Lacking the Psd Protein Rich2." Mol Brain 9 (Mar 11): 28. https://dx.doi.org/10.1186/s13041-016-0206-6.

Schoen, M., H. Asoglu, H. F. Bauer, H. P. Muller, A. Abaei, A. K. Sauer, .. T. M. Boeckers. 2019. "Shank3 Transgenic and Prenatal Zinc-Deficient Autism Mouse Models Show Convergent and Individual Alterations of Brain Structures in Mri." Front Neural Circuits 13: 6. https://dx.doi.org/10.3389/fncir.2019.00006.

Sestan, N., and M. W. State. 2018. "Lost in Translation: Traversing the Complex Path from Genomics to Therapeutics in Autism Spectrum Disorder." Neuron 100, no. 2 (Oct 24): 406-423. https://dx.doi.org/10.1016/j.neuron.2018.10.015.

Shen, W., M. B. C. Kilander, M. S. Bridi, J. A. Frei, R. F. Niescier, S. Huang, and Y. C. Lin. 2020. "Tomosyn Regulates the Small Rhoa Gtpase to Control the Dendritic Stability of Neurons and the Surface Expression of Ampa Receptors." J Neurosci Res 98, no. 6 (Jun): 1213-1231. https://dx.doi.org/10.1002/jnr.24608.

Silverman, J. L., and J. Ellegood. 2018. "Behavioral and Neuroanatomical Approaches in Models of Neurodevelopmental Disorders: Opportunities for Translation." Curr Opin Neurol 31, no. 2 (Apr): 126-133. https://dx.doi.org/10.1097/WCO.0000000000000537.

Silverman, J. L., S. S. Tolu, C. L. Barkan, and J. N. Crawley. 2010. "Repetitive Self-Grooming Behavior in the Btbr Mouse Model of Autism Is Blocked by the Mglur5 Antagonist Mpep." Neuropsychopharmacology 35, no. 4 (Mar): 976-89. https://dx.doi.org/10.1038/npp.2009.201.

Sledziowska, M., J. Galloway, and S. J. Baudouin. 2019. "Evidence for a Contribution of the Nlgn3/Cyfip1/Fmr1 Pathway in the Pathophysiology of Autism Spectrum Disorders." Neuroscience (Nov 6). https://dx.doi.org/10.1016/j.neuroscience.2019.10.011.

Smogavec, M., A. Cleall, J. Hoyer, D. Lederer, M. C. Nassogne, E. E. Palmer, . . C. Zweier. 2016. "Eight Further Individuals with Intellectual Disability and Epilepsy Carrying Bi-Allelic Cntnap2 Aberrations Allow Delineation of the Mutational and Phenotypic Spectrum." J Med Genet 53, no. 12 (Dec): 820-827. https://dx.doi.org/10.1136/jmedgenet-2016-103880.

Stessman, H. A., T. N. Turner, and E. E. Eichler. 2016. "Molecular Subtyping and Improved Treatment of Neurodevelopmental Disease." Genome Med 8, no. 1 (Feb 25): 22. https://dx.doi.org/10.1186/s13073-016-0278-z.

Sui, L., and M. Chen. 2012. "Prenatal Exposure to Valproic Acid Enhances Synaptic Plasticity in the Medial Prefrontal Cortex and Fear Memories." Brain Res Bull 87, no. 6 (Apr 10): 556-63. https://dx.doi.org/10.1016/j.brainresbull.2012.01.011.

Szklarczyk, D., A. Franceschini, S. Wyder, K. Forslund, D. Heller, J. Huerta-Cepas, . . C. von Mering. 2015. "String V10: Protein-Protein Interaction Networks, Integrated over the Tree of Life." Nucleic Acids Res 43, no. Database issue (Jan): D447-52. https://dx.doi.org/10.1093/nar/gku1003. 
Szklarczyk, D., A. L. Gable, D. Lyon, A. Junge, S. Wyder, J. Huerta-Cepas, . . C. V. Mering. 2019. "String V11: Protein-Protein Association Networks with Increased Coverage, Supporting Functional Discovery in Genome-Wide Experimental Datasets." Nucleic Acids Res 47, no. D1 (Jan 8): D607-D613. https://dx.doi.org/10.1093/nar/gky1131.

Sztainberg, Y., and H. Y. Zoghbi. 2016. "Lessons Learned from Studying Syndromic Autism Spectrum Disorders." Nat Neurosci 19, no. 11 (Oct 26): 1408-1417. https://dx.doi.org/10.1038/nn.4420.

Tang, B., T. Wang, H. Wan, L. Han, X. Qin, Y. Zhang, . . L L. Liao. 2015. "Fmr1 Deficiency Promotes Age-Dependent Alterations in the Cortical Synaptic Proteome." Proc Natl Acad Sci U S A 112, no. 34 (Aug 25): E4697-706. https://dx.doi.org/10.1073/pnas.1502258112.

Thompson, A., J. Schafer, K. Kuhn, S. Kienle, J. Schwarz, G. Schmidt, . . C. Hamon. 2003. "Tandem Mass Tags: A Novel Quantification Strategy for Comparative Analysis of Complex Protein Mixtures by Ms/Ms." Anal Chem 75, no. 8 (Apr 15): 1895-904. https://dx.doi.org/10.1021/ac0262560.

Tian, C., Y. Kay, A. Sadybekov, S. Rao, V. Katritch, and B. E. Herring. 2018. "An Intellectual Disability-Related Missense Mutation in Rac1 Prevents Ltp Induction." Front Mol Neurosci 11: 223. https://dx.doi.org/10.3389/fnmol.2018.00223.

Tindi, J. O., A. E. Chavez, S. Cvejic, E. Calvo-Ochoa, P. E. Castillo, and B. A. Jordan. 2015. "Anks1b Gene Product Aida-1 Controls Hippocampal Synaptic Transmission by Regulating Glun2b Subunit Localization." J Neurosci 35, no. 24 (Jun 17): 8986-96. https://dx.doi.org/10.1523/JNEUROSCI.4029-14.2015.

Tyanova, S., T. Temu, and J. Cox. 2016. "The Maxquant Computational Platform for Mass Spectrometry-Based Shotgun Proteomics." Nat Protoc 11, no. 12 (Dec): 2301-2319. https://dx.doi.org/10.1038/nprot.2016.136.

Vallianatos, C. N., C. Farrehi, M. J. Friez, M. Burmeister, C. E. Keegan, and S. Iwase. 2018. "Altered Gene-Regulatory Function of Kdm5c by a Novel Mutation Associated with Autism and Intellectual Disability." Front Mol Neurosci 11: 104. https://dx.doi.org/10.3389/fnmol.2018.00104.

Varghese, M., N. Keshav, S. Jacot-Descombes, T. Warda, B. Wicinski, D. L. Dickstein, . . P. R. Hof. 2017. "Autism Spectrum Disorder: Neuropathology and Animal Models." Acta Neuropathol 134, no. 4 (Oct): 537-566. https://dx.doi.org/10.1007/s00401-017-1736-4.

Verma, V., A. Paul, A. Amrapali Vishwanath, B. Vaidya, and J. P. Clement. 2019. "Understanding Intellectual Disability and Autism Spectrum Disorders from Common Mouse Models: Synapses to Behaviour." Open Biol 9, no. 6 (Jun 28): 180265. https://dx.doi.org/10.1098/rsob.180265.

Vogel, C., and E. M. Marcotte. 2012. "Insights into the Regulation of Protein Abundance from Proteomic and Transcriptomic Analyses." Nat Rev Genet 13, no. 4 (Mar 13): 227-32. https://dx.doi.org/10.1038/nrg3185. 
1313

1314

1315

1316

1317

1318

1319

1320

1321

1322

1323

1324

1325

1326

1327

1328

1329

1330

1331

1332

1333

1334

1335

1336

1337

1338

1339

1340

1341

1342

1343

1344

1345

1346

1347

1348

1349

1350

1351

1352

1353

1354

1355

1356

1357

1358

1359

1360

Wang, R., J. Tan, J. Guo, Y. Zheng, Q. Han, K. F. So, . . L. Zhang. 2018. "Aberrant Development and Synaptic Transmission of Cerebellar Cortex in a Vpa Induced Mouse Autism Model." Front Cell Neurosci 12: 500. https://dx.doi.org/10.3389/fncel.2018.00500.

Wei, D., D. Dinh, D. Lee, D. Li, A. Anguren, G. Moreno-Sanz, . . D. Piomelli. 2016. "Enhancement of Anandamide-Mediated Endocannabinoid Signaling Corrects Autism-Related Social

Impairment." Cannabis Cannabinoid Res 1, no. 1: 81-89. https://dx.doi.org/10.1089/can.2015.0008.

Weiner, D. J., E. M. Wigdor, S. Ripke, R. K. Walters, J. A. Kosmicki, J. Grove, . . E. B. Robinson. 2017. "Polygenic Transmission Disequilibrium Confirms That Common and Rare Variation Act Additively to Create Risk for Autism Spectrum Disorders." Nat Genet 49, no. 7 (Jul): 978-985. https://dx.doi.org/10.1038/ng.3863.

Xiao, Y., Y. Peng, J. Wan, G. Tang, Y. Chen, J. Tang, .. . L. Shi. 2013. "The Atypical Guanine Nucleotide Exchange Factor Dock4 Regulates Neurite Differentiation through Modulation of Rac1 Gtpase and Actin Dynamics." J Biol Chem 288, no. 27 (Jul 5): 20034-45. https://dx.doi.org/10.1074/jbc.M113.458612.

Yan, J., M. W. Porch, B. Court-Vazquez, M. V. L. Bennett, and R. S. Zukin. 2018. "Activation of Autophagy Rescues Synaptic and Cognitive Deficits in Fragile X Mice." Proc Natl Acad Sci U S $A$ 115, no. 41 (Oct 9): E9707-E9716. https://dx.doi.org/10.1073/pnas.1808247115.

Zamboni, V., M. Armentano, G. Berto, E. Ciraolo, A. Ghigo, D. Garzotto, . . G. R. Merlo. 2018 a. "Hyperactivity of Rac1-Gtpase Pathway Impairs Neuritogenesis of Cortical Neurons by Altering Actin Dynamics." Sci Rep 8, no. 1 (May 8): 7254. https://dx.doi.org/10.1038/s41598-018-25354$\underline{3}$.

Zamboni, V., M. Armentano, G. Saro, E. Ciraolo, A. Ghigo, G. Germena, .. G. R. Merlo. 2016. "Disruption of Arhgap15 Results in Hyperactive Rac1, Affects the Architecture and Function of Hippocampal Inhibitory Neurons and Causes Cognitive Deficits." Sci Rep 6 (Oct 7): 34877. https://dx.doi.org/10.1038/srep34877.

Zamboni, V., R. Jones, A. Umbach, A. Ammoni, M. Passafaro, E. Hirsch, and G. R. Merlo. 2018b. "Rho Gtpases in Intellectual Disability: From Genetics to Therapeutic Opportunities." Int J Mol Sci 19, no. 6 (Jun 20). https://dx.doi.org/10.3390/ijms 19061821.

Zamurrad, S., H. A. M. Hatch, C. Drelon, H. M. Belalcazar, and J. Secombe. 2018. "A Drosophila Model of Intellectual Disability Caused by Mutations in the Histone Demethylase Kdm5." Cell Rep 22, no. 9 (Feb 27): 2359-2369. https://dx.doi.org/10.1016/j.celrep.2018.02.018.

Zeidan-Chulia, F., B. N. de Oliveira, M. F. Casanova, E. L. Casanova, M. Noda, A. B. Salmina, and A. Verkhratsky. 2016. "Up-Regulation of Oligodendrocyte Lineage Markers in the Cerebellum of Autistic Patients: Evidence from Network Analysis of Gene Expression." Mol Neurobiol 53, no. 6 (Aug): 4019-4025. https://dx.doi.org/10.1007/s12035-015-9351-7.

Zeidan-Chulia, F., J. L. Rybarczyk-Filho, A. B. Salmina, B. H. de Oliveira, M. Noda, and J. C. Moreira. 2013. "Exploring the Multifactorial Nature of Autism through Computational Systems Biology: 
bioRxiv preprint doi: https://doi.org/10.1101/2021.02.02 429412; this version posted February 2, 2021. The copyright holder for this preprint

(which was not certified by peer review) is the author/funder, who has granted bioRxiv a license to display the preprint in perpetuity. It is made available under aCC-BY-NC-ND 4.0 International license.

1361

1362

1363

1364

1365

1366

1367

1368

1369

1370

1371

1372

1373

1374

Calcium and the Rho Gtpase Rac1 under the Spotlight." Neuromolecular Med 15, no. 2 (Jun): 364-83. https://dx.doi.org/10.1007/s12017-013-8224-3.

Zhou, Y., T. Kaiser, P. Monteiro, X. Zhang, M. S. Van der Goes, D. Wang, ... G. Feng. 2016. "Mice with Shank3 Mutations Associated with Asd and Schizophrenia Display Both Shared and Distinct Defects." Neuron 89, no. 1 (Jan 6): 147-62.

https://dx.doi.org/10.1016/j.neuron.2015.11.023.

Zoghbi, H. Y., and M. F. Bear. 2012. "Synaptic Dysfunction in Neurodevelopmental Disorders Associated with Autism and Intellectual Disabilities." Cold Spring Harb Perspect Biol 4, no. 3 (Mar 1). https://dx.doi.org/10.1101/cshperspect.a009886. 